\title{
Kapadokya Bölgesi Duvar Resimlerinde Kutsal Anlam Taşıyan ve Apotropaik Etkili Motifler*
}

\section{Motifs with Sacred and Apotropaic Meanings on the Wall Paintings of Cappadocia Region}

\section{Metin Kaya*}

\section{Öz}

Roma kültüründen devam eden Pagan inançlı ve apotropaik anlamlı unsurların erken Hristiyan toplumunda devamlılık göstermesinin sanatsal üretime yansıdığı gözlemlenmektedir. Pagan inancının izlerini taşıyan Medusa başı, mask gibi temalar Hristiyan ustalar tarafından dekoratif amaçlı kullanılmaya devam ettirilmiştir. Bunun yanında, yeni Bizans sanatının kendine ait bezeme dekorasyonu içerisinde Hristiyan inancına uygun şekilde aynı anlam taşıyan motiflerin kullanımı da görmek mümkündür.

Bölgede duvar resimlerini yapan sanatçıların çoğunluğunun Helenistik gelenekler ve Hristiyan bilgilerine sahip yerli ustalar olduğu anlaşılmaktadır. Bizanslı sanatçılar kutsal anlam taşıyan ve apotropaik etkiye sahip motifleri kilise içerisinde resmederken, Bizans estetiği ile de uyum içerisinde olmalarına önem vermişlerdir. Bu anlamda, Kapadokya bölgesi duvar resimlerinde orta ve geç Bizans dönemi duvar resimlerinde bazı anikonik motiflere kutsal anlam ve apotropaik etki eklendiği zaman izleyici açısından aslında ne kadar etkili olduğunu da unutmamak gerekmektedir.

Bu çalışmada özellikle Kapadokya bölgesinde orta ve geç Bizans dönemlerine tarihlendirilen kiliselerin duvar resimlerinde karşılaşılan yaprak mask, ay, güneş, sekiz kollu rozet, dönen disk ve madalyon, antrolak, üç boyutlu zikzak, değerli taşlar, rozet, gibi motiflerin kilise içerisinde konumları, renk kullanımları ile birlikte kutsal apotropaik anlamları üzerinde durulacaktır. Ayrıca, Kapadokyalı Kilise Babalarının doktrinlerinin bu duruma etkileri, dönemin el yazmaları ve duvar resimleri başta olmak üzere Bizans sanatı içerisinde sanat tarihsel çerçevede karşılaştırmalı bir değerlendirme yapılacaktır.

\section{Anahtar Kelimeler}

Bizans, Kapadokya, Duvar Resmi, Motif, Apotropaik

\section{Abstract}

In early Christian society, the continuation of pagan beliefs and apotropaic elements derived from the Roman culture can be observed in the reflections of artistic production. Apotropaic themes bearing the traces of paganism, such as the

* Bu çalışma İstanbul Üniversitesi Sosyal Bilimler Enstitüsü Sanat Tarihi Anabilim Dalı bünyesinde Prof. Dr. Asnu Bilban Yalçın danışmanlığında Metin Kaya tarafindan hazırlanan Kapadokya Bölgesi Duvar Resimlerinde Görülen Süsleme Motifleri: Bizans Sanat Içinde Karşılaştırmalı Değerlendirme başlıklı Doktora Tez çalışmasından üretilmiştir. "Kapadokya Bölgesi Duvar Resimlerinde Kutsal Anlam Taşıyan ve Apotropaik Etkili Motifler" başlığıyla 2020 yılında Nevşehir Hacı Bektaş Veli Üniversitesi tarafindan düzenlenen 24. Uluslararası Ortaçağ ve Türk Dönemi Kazıları ve Sanat Tarihi Araştırmaları Sempozyumu'nda bildiri olarak sunulmuştur.

** Sorumlu Yazar: Metin Kaya (Arş. Gör.), İstanbul Üniversitesi, Edebiyat Fakültesi, Sanat Tarihi Bölümü, İstanbul, Türkiye. E-posta: metin.kaya@istanbul.edu.tr, ORCID: 0000-0003-1368-7537

Atıf: Kaya, Metin. "Kapadokya Bölgesi Duvar Resimlerinde Kutsal Anlam Taşıyan ve Apotropaik Etkili Motifler." Art-Sanat, 16(2021): 409-435. https://doi.org/10.26650/artsanat.2021.16.0014 
Medusa head and the mask were used continuously for decorative purposes by Christian artists. These motifs also show apotropaic features aligning with the Christian faith in the decoration of the new Byzantine art.

We can see that the majority of artists who drew the wall paintings in the region were local artists socialized within Hellenistic traditions and with Christian knowledge. While painting the motifs with sacred meanings and apotropaic effects in the church, Byzantine artists focused on the harmony of these motifs with the Byzantine aesthetic. In this sense, it should not be forgotten how effective it is from a viewer's point of view to add a sacred meaning and apotropaic effects to these motifs in the Cappadocian wall paintings in the mid or late Byzantine era.

In our study, we will emphasize the motifs we have encountered in the wall paintings of churches, especially in the Cappadocia region, dating back to the middle and late Byzantine periods, such as leaf mask, moon, sun, eight-pointed rosette, rotating disk and medallion, guilloche, interlace, zigzag, three-dimensional folded plate, precious stones and their location within the church, their use of color, and their sacred apotropaic meaning. Moreover, an evaluation of the effects of the doctrines of Cappadocian church fathers on this situation in Byzantine art, especially about the manuscripts and wall paintings of the period, will be conducted by comparing the art within the material historical framework.

Keywords

Byzantine, Cappadocia, Wall Painting, Ornament, Apotropaic

\section{Extended Summary}

Pagan beliefs and apotropaic elements from the Roman culture are observed in the artistic productions of the early Christian community. Some elements of paganism, such as the Medusa head and the mask were used with apotropaic themes for decoration by Christian artists. The new Byzantine art itself shows these apotropaic features combined with the Christian faith within the decorative motifs.

The Cappadocia region is one of the few regions, which has the majority of the middle and late Byzantine period wall paintings that are still intact over time. As of the second half of the $11^{\text {th }}$ century, even though the Christians could not show artistic development in the region under Turkish domination, they continued their artistic production. Studies have revealed that despite the Turkish domination, there is no isolated art perception in the region in line with both architectural and painterly data due to the overt connection with the other Christian regions such as the areas that are populated by Armenian artists, the capital of Byzantine, and even Seljuk art movements. Therefore, the Byzantine decoration and repertoire of the period were reflected in the wall paintings of Cappadocia.

In our study, we will emphasize the motifs we have encountered on the wall paintings of churches, especially in the Cappadocia region, dating back to the middle and late Byzantine periods, such as the leaf mask, moon, sun, eight-pointed rosette, rotating disk and medallion, guilloche, interlace, zigzag, three-dimensional folded plate, precious stones and their location within the church, their use of color, and their sacred apotropaic meaning. Moreover, an evaluation of the effects of the doctrines of Cappadocian church fathers on this situation in the Byzantine art, especially around 
the manuscripts and wall paintings of the period, will be conducted by comparing the art within the material historical framework.

It is known that the symmetrical placement of circular patterns, rosettes, and cabochons on both sides of an arch is often considered a sign of holiness in both the Christian and Islamic worlds. The disk motif in Byzantine wall paintings that is connected with holiness often appeared on monumental icon frames in proskynetaria, architectural sculptures, manuscripts and canon tables of the Gospels, and on the architectural facades of eastern Christian buildings. Studies show that, in particular, rotating disk-shaped motifs, which were seen in the twelfth-century Byzantine wall paintings, gained popularity in the $13^{\text {th }}$ and $14^{\text {th }}$ centuries. The circle shapes symbolize infinity and perfection, and the rotating disk symbolizes sacred energy. It is often emphasized by researchers that this sign of holiness also has a protective function.

Some motifs indicate unique features in the region as on the arch paddings on the east facade of Bezirana Church (the end of the $13^{\text {th }}$ century and the beginning of the $14^{\text {th }}$ century). The red disk in the north direction of the east wall represents the Sun, and the gray-blue disk in the south direction represents the Moon. It is known that Saint Basil, one of the Cappadocian Church Fathers, used these expressions in this respect in his sermons. In addition, these disk motifs consist of three centers and move with rotating lines of different hues in their interior-creating the impression of a rotating motif. The tricentricity of the disks can be thought of as a reference to the trinity; in fact, the higher positioning of the disks gives us more precise results in terms of their divine character.

As a different variation of the rotating disk motifs, we encounter wheel of fortune motifs in the Kızılçukur Yohakim and Anna Church ( $9^{\text {th }}$ century) and the Ihlara Y1lanl Church $\left(9^{\text {th }}-10^{\text {th }}\right.$ century). As with the rotating disk motifs, this motif can also be considered to have the same theological and apotropaic effects. Considering all this information, it is understood that divine light and sacred energy have an important reality in eastern Christianity. Therefore, we can also think of these motifs as symbols of sacred energy and tools that radiate sacred energy in temples. In some of the columned churches -the Karanlik Church ( $11^{\text {th }}$ century), the Elmalı Church ( $11^{\text {th }}$ century), and the Çarıklı Church (1 $11^{\text {th }}$ century)- the acanthus motif, which we examined in the category of floral motif, is painted. Based on the special little thorns of this sacred herbaceous plant, Christianity attributes to this sacred herbaceous plant as a symbolic meaning ascribed to human suffering regarding sin and repentance in line with the biblical texts and descriptions of the church fathers. Unlike the other churches in the Cappadocia region, the acanthus motifs in the aforementioned three churches are spiral and cover large surfaces, and it is obvious that they are preferred to be used in the upper cover units by the artists. In this sense, except for the areas reserved for iconographic scenes, 
the use of the motif on top cover surfaces raises a question: "Was there a relationship between its semantic function and architecture? " However, altogether, it is understood that the artists have the idea and desire to decorate the large surfaces with the most appropriate acanthus tendril and in eye-catching (aesthetic) ways.

We can see that the majority of artists who drew the wall paintings in the region were local artists socialized within Hellenistic traditions and Christian knowledge. While Byzantine artists gave the sacred meaning and apotropaic motifs (as mentioned above) in the church, they also gave importance to the need to be in harmony with Byzantine aesthetics. In this sense, we can understand the effectiveness from a viewer's perspective of adding a sacred meaning and apotropaic effect to some aniconic motifs in the Cappadocian wall paintings in the middle and late Byzantine period. 


\section{Giriş}

Kapadokya'nın geniş anıtsal duvar freskleri repertuvarında figüratif kutsal temaların yer aldığı geniş yüzeylerin kimi zaman çerçevelerinde kimi zaman da serbest konumlarda görülen süsleme motifleri arasında sembolik olarak anlam taşıyan bazı desenler, araştırmacılar tarafından genel bağlam içinde ele alınmış ancak bunların işaret edebilecekleri anlamlar üzerine durulmamıştır. Teolojik alanda, genellikle tüm semavi dinlerde belirli işaret ve motiflerin öğretici, eskatolojik ${ }^{1}$ ve apotropaik ${ }^{2}$ açılımları olması din teologları tarafından ağırlıkla çalışılmakla birlikte, sanat tarihi alanında sadece belirgin olduğu müddetçe ele alınmaktadır.

Bizans dünyasında da kimi sembol ve işaretlerin Hristiyan anlamlar yüklendiği bilinmekte ve bunların tasvir sanatlarında genel ikonografi ile uyuşma sorunlarının çözümü beklenmektedir.

Bu makalede, Bizans dönemi Kapadokya duvar resimlerinden seçilen bazı motiflerin taşıdıkları anlamlar ve orijinleri üzerine giriş yapmak amaçlanmıştır.

\section{Kapadokya Bölgesindeki Apotropaik Etkili Motifler Üzerine Değerlendirmeler}

Bezirana Kilisesi, duvar resimlerinde apotropaik etki taşıdığ 1 düşünülen farklı motifleri bir arada bulundurması dolayısıyla Bizans dönemi Kapadokya ${ }^{3}$ kiliseleri arasında özel bir öneme sahiptir. Nitekim, nefin doğu duvarının kuzey ve güney kısmında yer alan gömme payelerin üzerinde birer aslan başı tasviri yer almaktadır (G.1, G. 2). Kapadokya üzerine önemli çalışmaları olan ve yakın bir zamanda kilisede incelemelerde bulunan C. Jolivet Levy, bu aslan başı tasvirlerinin stilize akanthus yapraklarından oluştuğunu, bu tip kullanımın erken Bizans dönemi mimari plastik eserlerinde yaygın işlendiğini ve özel bir uygulama ile de akanthus bitkisine etkileyici zoomorfik bir görünüm verildiğini düşünmektedir. ${ }^{4}$

Antikite kökenli bu desen, geç Bizans döneminde klasik bezeme repertuvarına ait motifler yeniden canlandırılmış ve Palaiologos dönemi sanatçıları tarafından da iyi algılanmış ve uygulanmıştır. ${ }^{5}$

1 Dünyanın sonunun kozmolojik beklentisi, bireysel ölüm beklentisi ve ölümden sonraki dünya (Cehennem veya Cennet) kavramlarına karşılık gelmektedir. Detaylı bilgi için bk. Gerhard Podskalsky, "Eschatology," Oxford Dictionary of Byzantium, Vol. I, ed. Alexander Khazdan (New York: Oxford Press, 1991), 728.

2 Kötülüğü uzaklaştırıcı veya kötülüklerden koruyucu işaret, motif, yazı vb. nesne olarak tanımlanabilmektedir. Detaylı bilgi için bk. “Apotropaico,” Treccani, erişim 11 Haziran 2021, https://www.treccani.it/enciclopedia/ apotropaico

3 Kapadokya’nın Bizans dönemi kısa tarihçesi için bk. Metin Kaya, "Reflection of the Islamic and Sassanid Art on the Aniconic Decoration of Byzantine wall paintings in Cappadocia," International Symposium of Byzantologists Nis and Byzantium XVIII, ed. Miša Rakocija (Nis: Cultural Center of Nis, 2020), 339.

4 C. Jolivet Levy, "Bezirana Kilisesi (Cappadoce). Un Exceptionnel Decor Paleologue en teres de Rum. Nouveau Temoigage sur les Relations Entre Byzance et Le Sultanat," Zograf 41 (2017), 123.

5 Doula Mouriki, "The Mask Motif in the Wall Paintings of Mistra. Cultural Implications of a Classical Feature in Late Byzantine Painting,” Deltion tes Christianikes Archaiologikes Hetaireias 10 (1980-1981), 337; Levy, 


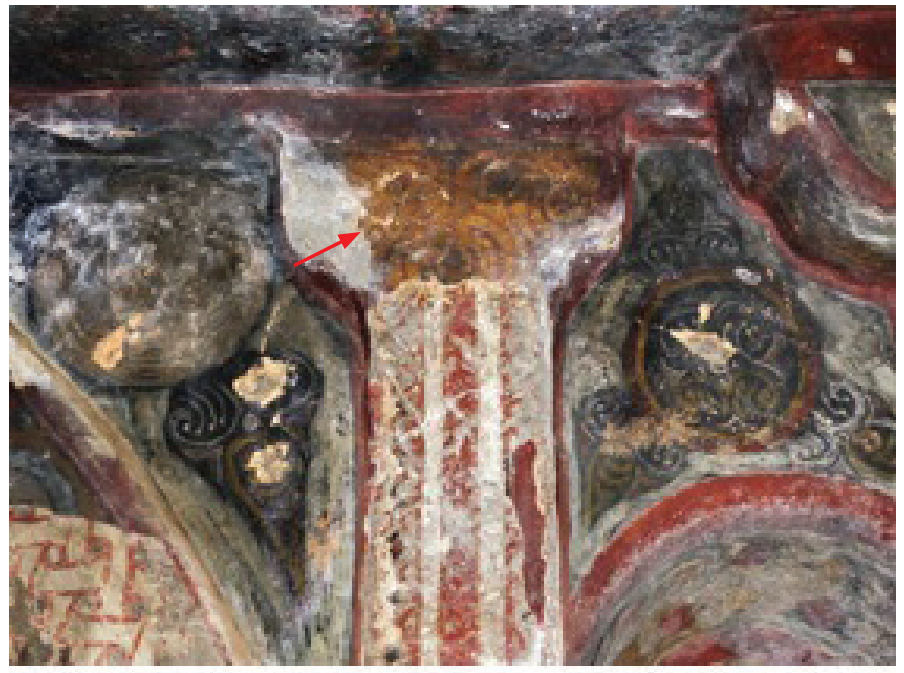

G.1. Bezirana Kilisesi, geç 13. yüzyıl -erken 14. yüzyıl, doğu duvarın güney kısmı (J. Levy, "Bezirana Kilisesi (Cappadoce)", 123)

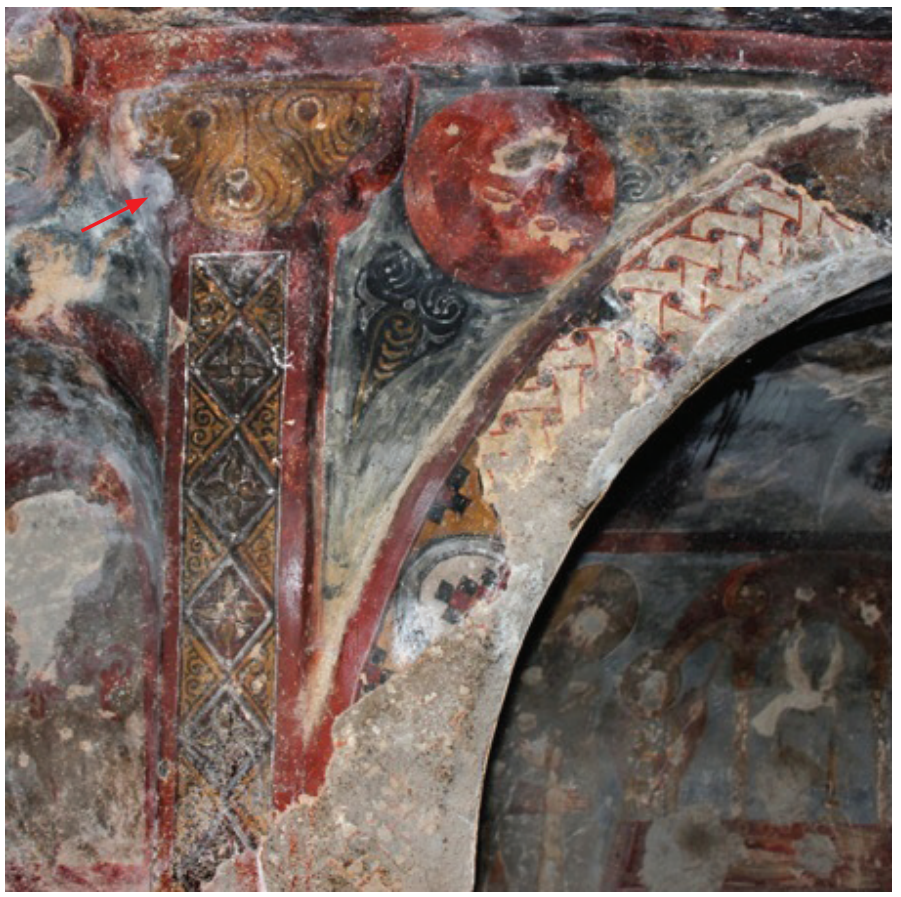

G.2. Bezirana Kilisesi, geç 13. yüzyıl - erken 14. yüzyıl), doğu duvarın kuzey kısmı (J. Levy, "Bezirana Kilisesi (Cappadoce)”,122)

"Bezirana Kilisesi (Cappadoce). Un Exceptionnel Decor Paleologue en teres de Rum. Nouveau Temoigage sur les Relations Entre Byzance et Le Sultanat," 123. Mask motiflerinin Bizans sanatında 7. yüzyıla kadar yoğun kullanıldığı ve Geç Antik Çağ sonrasında ilk defa Makedonyalılar Hanedanlığı döneminde görülmeye başladığı bilinmektedir. Detaylı bilgi için bk. Mouriki, "The Mask Motif in the Wall Paintings of Mistra. Cultural Implications of a Classical Feature in Late Byzantine Painting," 317. 
Özellikle Konstantinopolis ve başkent ile yakın bağlantıları olan İmparatorluğun diğer bölgelerinde, örneğin Mistras, Selanik ile Sırbistan, Palaiologoslar dönemi sanat1, elit bir sanat zevkini yansitarak ve muhtemelen hâlâ Antik Çağ'ın apotropaik anlamı bu dönemde de devam ettirmiştir. Mabedin girişinden net görülen akanthus yapraklarından oluşan bu aslan başı tasvirlerinin koruyucu gücü, özellikle Kilikya'dan 13. yüzyıl sonu 14. yüzyıl başı tarihli aslan başı motiflerinin yaygın kullanıldığı Ermeni el yazmalarında (G. 3) ve İncillerin kanon tablolarında (G. 4) olduğu gibi İsa'nın Kutsal gücüne gönderme yapmaktadır. ${ }^{6}$

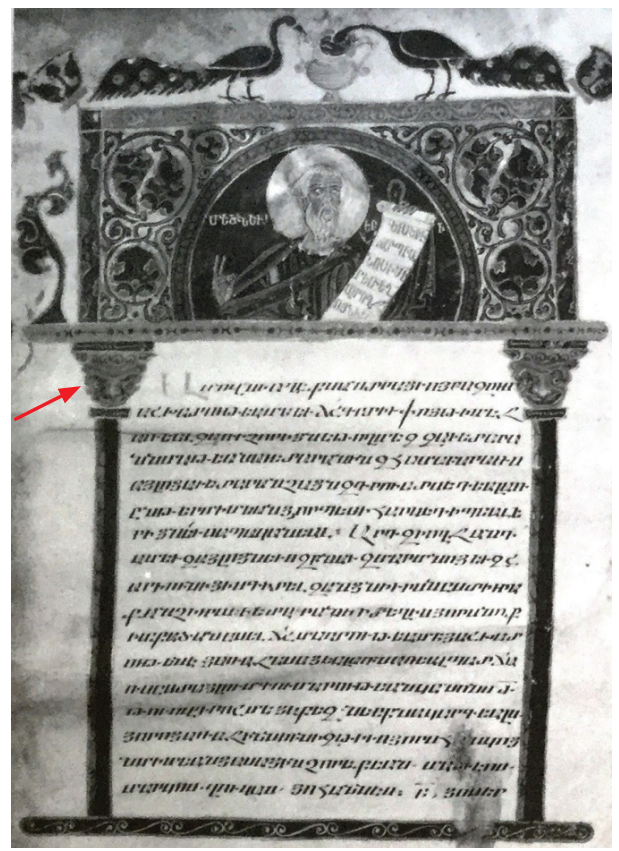

G.3. Eusebius'un Mektubu, Kudüs Ermeni Patrikhanesi 1796, fol.6, 12. yüzy1l (S. Der Nersessian, Miniature Painting in the Armenian Kingdom of Clicia, Vol. II, fig. 54)

6 Levy, "Bezirana Kilisesi (Cappadoce). Un Exceptionnel Decor Paleologue en teres de Rum. Nouveau temoigage sur les relations entre Byzance et Le Sultanat, 123.” 12-13. 13 ve 14. yüzyılda aslan başı tasviri Selçuklu, Ermeni ve Gürcü mimari bezemesinde kullanılması gücün sembolü olarak görülmektedir. Bk. Levy, "Bezirana Kilisesi (Cappadoce). Un Exceptionnel Decor Paleologue en teres de Rum. Nouveau temoigage sur les relations entre Byzance et Le Sultanat," 123. Ayrıca, Mouriki yaptığ 1 araştırmalarda; Hristiyan sanatında karşılaştığımız akanthus yapraklarından oluşan aslan başı tasvirlerinin Konstantinopolis kökenli olduğunu ve doğrudan ya da dolaylı olarak başkentten imparatorluğun diğer bölgelerine yayıldığını öne sürmektedir. Bk. Mouriki, "The Mask Motif in the Wall Paintings of Mistra. Cultural Implications of a Classical Feature in Late Byzantine Painting," 322 ve 328; Levy, "Bezirana Kilisesi (Cappadoce). Un Exceptionnel Decor Paleologue en teres de Rum. Nouveau temoigage sur les relations entre Byzance et Le Sultanat," 122-123. Tüm bunların yanı sıra Bezirana Kilisesi duvar resimlerinin başkent Konstantinopolis'i referans alan ve Bizans elit sınıfının en zengin soylu kurumları ile rekabet etme arzusunda olan yerel Rum bir bani tarafindan yaptırıldığ bilinmektedir. Bk. Levy, "Bezirana Kilisesi (Cappadoce). Un Exceptionnel Decor Paleologue en teres de Rum. Nouveau temoigage sur les relations entre Byzance et Le Sultanat," 142. Bu anlamda, Bezirana Kilisesinde karşılaştığımız akanthus yapraklarından oluşan aslan başı masklarının başkent etkisinde resmedildikleri ve 13-14. yüzyıl Kapadokyası'nda Bizanslı sanatçıların Selçuklu Türklerinin hoşgörülü hâkimiyeti altında başkent sanatı ile bağlarını tamamen koparmadığı ve izole olmadıkları açıkça anlaşılmaktadır. 


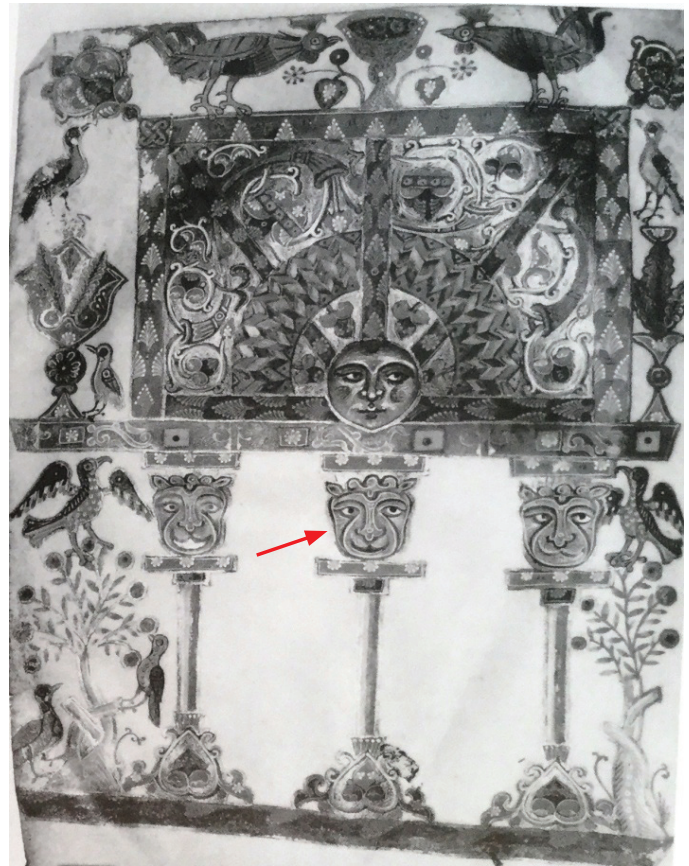

G.4. Kanon Tablo Çerçevesi, Galata St. Gregory Kilisesi, 35 Nolu El Yazması, Fol. 7v, 1223 (S. Der Nersessian, Miniature Painting in the Armenian Kingdom of Clicia, Vol. II, fig. 116)

Bizans sanatı içerisinde bir başka akanthus yaprakları ve aslan başı tasviri örneğini, günümüzde İstanbul Arkeoloji Müzesi’nde sergilenen ve 13 - 14. yüzyıla tarihlenen Marmara Adası mermerinden yapılmış çiftli impost başlıkta (G. 5) görebilmekteyiz. ${ }^{7}$ Bugün, Madri Halk Kütüphanesinde bulunan ve 12. yüzylla tarihlendirilen Skylitzes el yazmasında Nikephoras Phokas'ın tören ile Konstantinopolis'e giriși resmedilmiş, kenti simgeleyen altın kapının üzerinde bulunan sütun başlıklarında aslan başı tasvirlerine (G. 6) yer verilmiştir. ${ }^{8}$ Ayrıca, Khora manastırı kilisesinin parekklesion (1315-1321) orta kubbe dilimlerinde bordür olarak (G. 7), nefin güney duvarında aziz Prokopios figürünün kalkanında, ${ }^{9}$ Anastasis sahnesinde Adem'in kalktığı lahit üzerinde de bir aslan maskı (G. 8) dikkat çekmektedir. Mouriki, bu maskların çoğunun temelinin Medusa maskları olduğuna değinmekte ve Bizans sanatında karşılaştı̆̆ımız aslan başı gibi maskları; Medusa masklarının Hristiyanlık inancına uyarlanmış ve bo-

7 Nezih Firatl, La Sculpture figurée an musée archéologique d'Istanbul, ed. Catherine Metzger, vd. (Paris: Jean Maisonneuve Éditeur, 1990), Pl. 76 / 237; Asnu Bilban Yalçın, "Materiali di eta Paleologa nel Museo Archeologico di Istanbul," L'arte di Bisanzio e l'Italia al tempo dei Paleologi, Milion Studi e Ricerche di Arte Bizantina 5, (Roma: Argos, 1999), 363, res. 18.

8 Skylitzes el yazmasında Nikephoras Phokas'ın tören ile Konstantinopolis'e girişinin tasvir edildiği Madrid Skylitzes el yazması (Fol. 145r/b) için bk. Anđela Đ. Gavrilović, "The Representation Of Constantinople On The Folio 145r/B Of The Manuscript Of Madrid Skylitzes Synopsis Of Histories," International Symposium of Byzantologists Nis and Byzantium IV, ed. Miša Rakocija (Nis: Cultural Center of Nis, 2016), fig.1, 374.

9 Prokopios figürü kalkanında bulunan aslan başı tasviri için bk. Mouriki, "The Mask Motif in the Wall Paintings of Mistra. Cultural Implications of a Classical Feature in Late Byzantine Painting," P1.92/b 
zulmuş hâlleri olarak değerlendirmektedir. Bu bağlamda Mouriki, "motifin apotropaik etkisi nesnelerin işlevi açısından su götürmez bir gerçektir." "10 yorumunu yapmakta ve Bizans sanatında maskların yoğun kullanılmasının onun apotropaik etkisine bağlanabileceğini belirtmektedir. Roma sanatında Medusa masklarının ağırlıklı olarak lahit ve mezar stellerinde kullanılması onun psikopomp yani ölümden sonra ruhlara rehber ve ölülerin mezarlarının, ruhlarının sonsuz bir ikameti gerçekleştirmek üzere korunması işlevine bağlanmaktadır. ${ }^{11}$

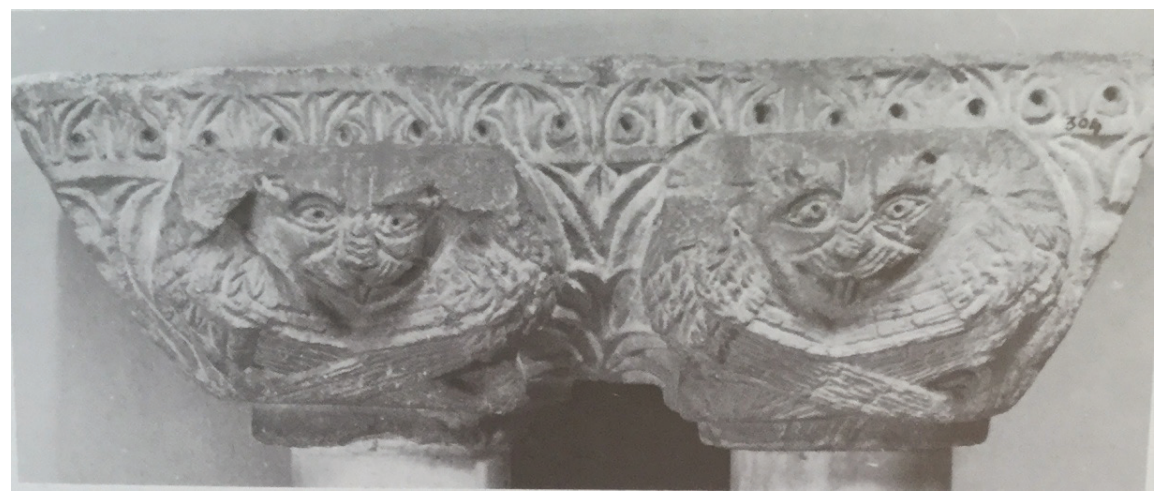

G.5. İstanbul Arkeoloji Müzesi, çift impost başlık, 13-14. yüzyı1, (N. Firatl1, La Sculpture Figurée an Musée Archéologique d'Istanbul, Pl. 76, fig. 237)

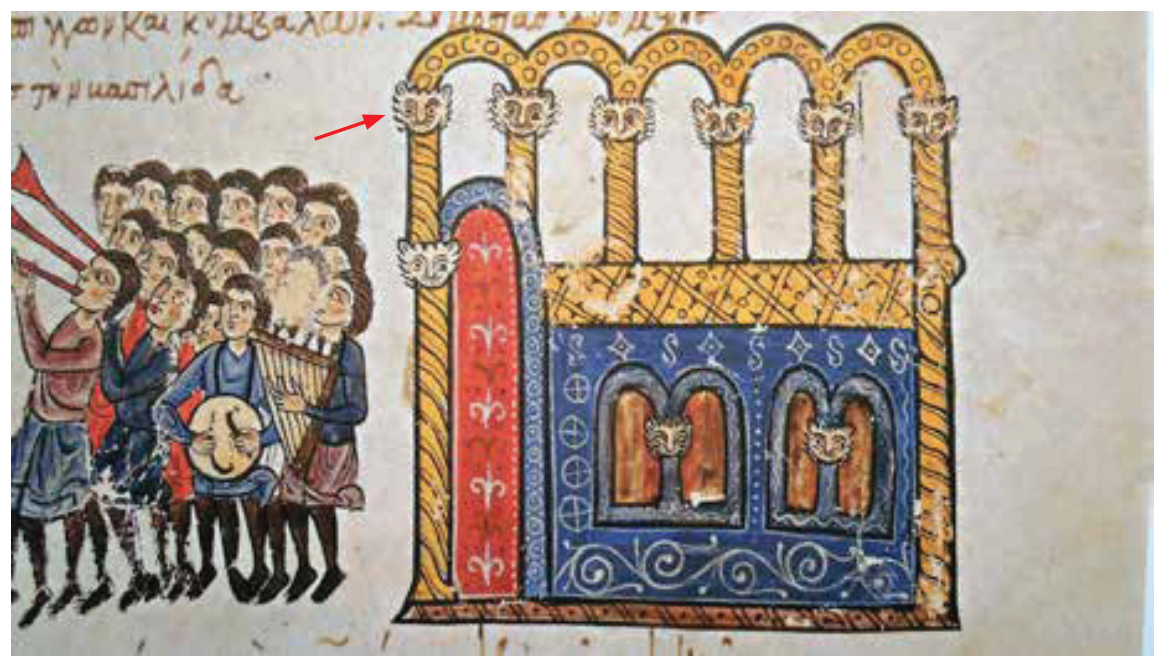

G.6. Skylitzes El Yazmas1, fol. 145r / b, 12. yüzyıl. (A. Gavrilovic, "The Representation of Constantinople on The Folio 145r/b of The Manuscript of Madrid Skylitzes Synopsis of

Histories", 374)

10 Mouriki, "The Mask Motif in the Wall Paintings of Mistra. Cultural Implications of a Classical Feature in Late Byzantine Painting," 336-337.

11 Bebina Milovanovic ve Jelena Anđelković Grašar, "Female Power That Protects: Examples of The Apotropaic and Decorative Functions of The Medusa in Roman Visual Culture From The Territory of The Central Balkans," Starinar 67 (2017), 168-169. 


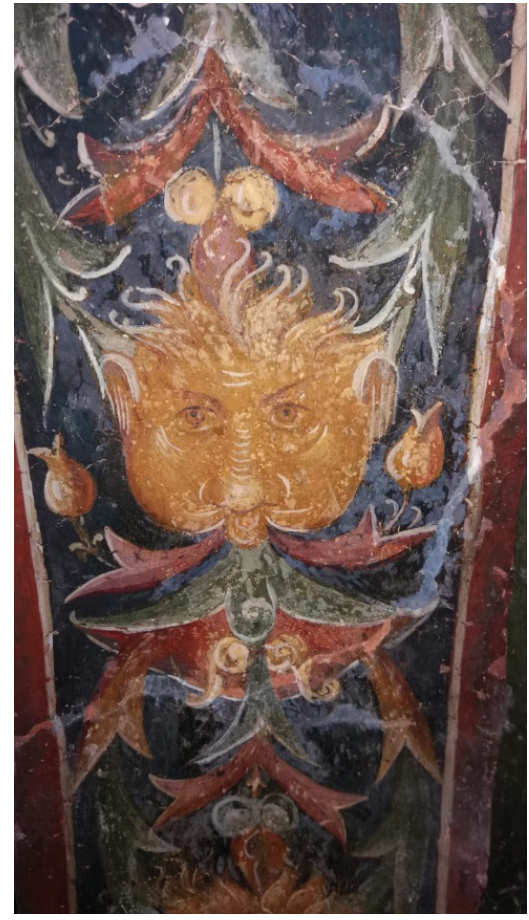

G.7. Khora manastırı kilisesi, parekklesion, orta kubbe dilimi bordürü, mask detayı (A. B. Yalçın arşivi, 2020)

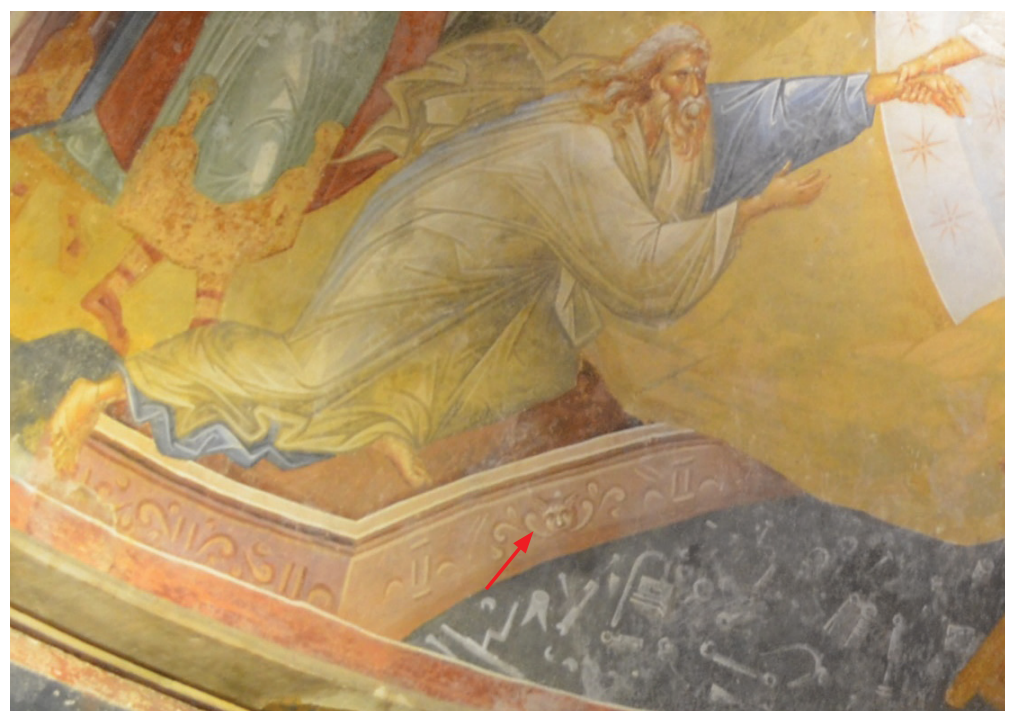

G.8. Khora manastırı kilisesi, Anastasis sahnesinde Ademin kalktığı lahit üzerinde bulunan aslan maskı (M. Kaya arşivi, 2017) 
Dairesel desenlerin, rozetler ve kaboşonların bir kemerin her iki yanında simetrik olarak yerleştirilmesinin hem Hristiyan hem de İslam dünyas ${ }^{12}$ için kutsallı̆̆ın bir işareti olarak değerlendirildiği bilinmektedir. ${ }^{13}$ Disk motifi, Bizans sanatında duvar resimlerinde ${ }^{14}$ (G. 9), mimari plastikte; sıkça anıtsal ikona çerçeveleri proskynetaria (G.10), el yazmaları ve İncillerin kanon tablolarında (G. 11), yine kutsallıkla bağlantılı olarak doğu Hristiyan yapılarının mimari cephelerinde karşımıza çıkmaktadır. Yapılan çalışmalar, özellikle dönen disk şeklindeki motiflerin Bizans duvar resimlerinde 12. yüzyılda görüldüğünü ve 13 ve 14. yüzyılda da yaygınlık kazandığını ortaya koymaktadır. ${ }^{15}$ Daire şekilleri sonsuzluğu ve mükemmelliğ $i,{ }^{16}$ dönen disk ise kutsal enerjiyi ${ }^{17}$ sembolize etmektedir. Bu kutsallığın işaretinin aynı zamanda koruyucu bir fonksiyon özelliği de taşıdığ 1 konusu araştırmacılar tarafından da sıkça vurgulanmaktadır. ${ }^{18}$

12 Bu tip motiflerin Anadolu İslam sanatındaki bazı örnekleri için bk. Oktay Aslanapa, Turkish Art and Architecture (Ankara: Atatürk Kültür Merkezi Yayınları, 2004), fig. 30, 31, 35, 61, 62, 211; Gönül Öney, "Sun and Moon Rosettes in The Shape of Human Heads in Anatolian Seljuk Architecture," Anatolica III, (1969-1970), fig. 1-21.

13 Bk. Levy, "Bezirana Kilisesi (Cappadoce). Un Exceptionnel Decor Paleologue en teres de Rum. Nouveau temoigage sur les relations entre Byzance et Le Sultanat," 123.

14 Disk motifleri üzerine araştırmalar yapan A. Ratseva ve V. Tarnovo, Bizans satında disk motiflerinin toplam 19 adet olduğunu, bunlardan onunun başkent Latinler tarafından işgal altında iken resmedildiğini belirtmektedir. Ancak, bu sayılara Kapadokya duvar resimlerinde karşılaştığımız disk motiflerinin dâhil edilmediği anlaşılmaktadır. Detaylı bilgi için bk. Avetozara Ratseva ve Velike Tarnovo, "The Mural Spinning Discs an Indication for Spiritual Connections and Artistic Influences,” Series Byzantina XI (2013), 27.

15 Ellen C. Schwartz, "The Whirling Disc: A Possible Connection between Medieval Balkan Frescoes and Byzantine Icon," Zograf 8, (1977), 26-27; Levy, "Bezirana Kilisesi (Cappadoce). Un Exceptionnel Decor Paleologue en teres de Rum. Nouveau temoigage sur les relations entre Byzance et Le Sultanat,” 125. Disk motifleri güneş ve ay biçiminde sıkça İran ve Anadolu Selçuklu sanatında da görülmektedir. Özellikle, Türk sanatında görülen bu tip motifler Türk-İslam sanatı araştırmacıları tarafından Orta Asya'dan etkilenen Şaman gelenekleri ve gökyüzü kültü hatırlatıcısı olarak yorumlanmaktadır. Detaylı bilgi için bk. Gönül Öney, "Sun and Moon Rosettes in The Shape of Human Heads in Anatolian Seljuk Architecture," Anatolica III, (19691970), 202-203.

16 Anne Karahan, "The Image of God in Byzantine Cappadocia and the Issue of Supreme Transcendence," Studia Patristica 7 (Leuven-Paris-Walpole: Peeters Publishers, 2013), 105; Levy, "Bezirana Kilisesi (Cappadoce). Un Exceptionnel Decor Paleologue en teres de Rum. Nouveau temoigage sur les relations entre Byzance et Le Sultanat," 125.

17 Ayrıca, Lomnica / Lovnika Aziz George Manastır Kilisesi (1608) duvar resimlerinde yer alan disk motiflerinde bulunan yazıtta Tanrının sözü ifadesinin geçmesi gibi nedenlerden dolayı S. Radajcic ve diğer bazı araştırmacılar disk motifinin Logos'u (Tanrı sözünü, yani İsa'yı) sembolize ettiği üzerinde dururken E. Schwartz gibi bazı araştırmacılar da bu görüşe temkinli yaklaşmaktadır. Detaylı bilgi için bk. Svetozar Radojčić, Mileševa, (Beograd: Srpska književna zadruga, 1963), 61, not 12; Ellen C. Schwartz, "The Whirling Disc: A Possible Connection between Medieval Balkan Frescoes and Byzantine Icon," 27-28; Levy, "Bezirana Kilisesi (Cappadoce). Un Exceptionnel Decor Paleologue en teres de Rum. Nouveau temoigage sur les relations entre Byzance et Le Sultanat," 125.

18 Levy, "Bezirana Kilisesi (Cappadoce). Un Exceptionnel Decor Paleologue en teres de Rum. Nouveau temoigage sur les relations entre Byzance et Le Sultanat," 125; Panayonis St. Katsafodos, "New Epigraphic Evidence From Mani The Kaphiona Epigrams," Deltion tes Christianikes Archaiologikes Hetaireias 38 (2017), 42-43. 


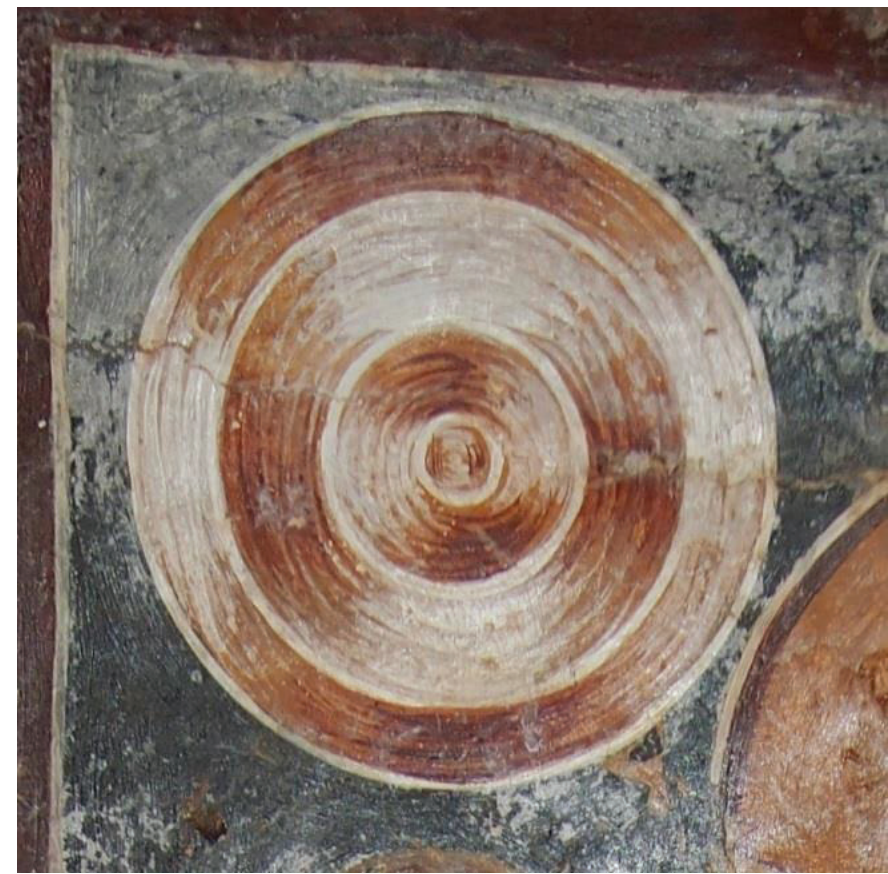

G. 9. Mani-Kafiona Hagioi Theodoroi Kilisesi, 1263-64, apsis duvar resmi, dönen disk motifi (P. Katsafados, New Epigraphic Evidence From Mani The Kaphiona Epigrams, 40)

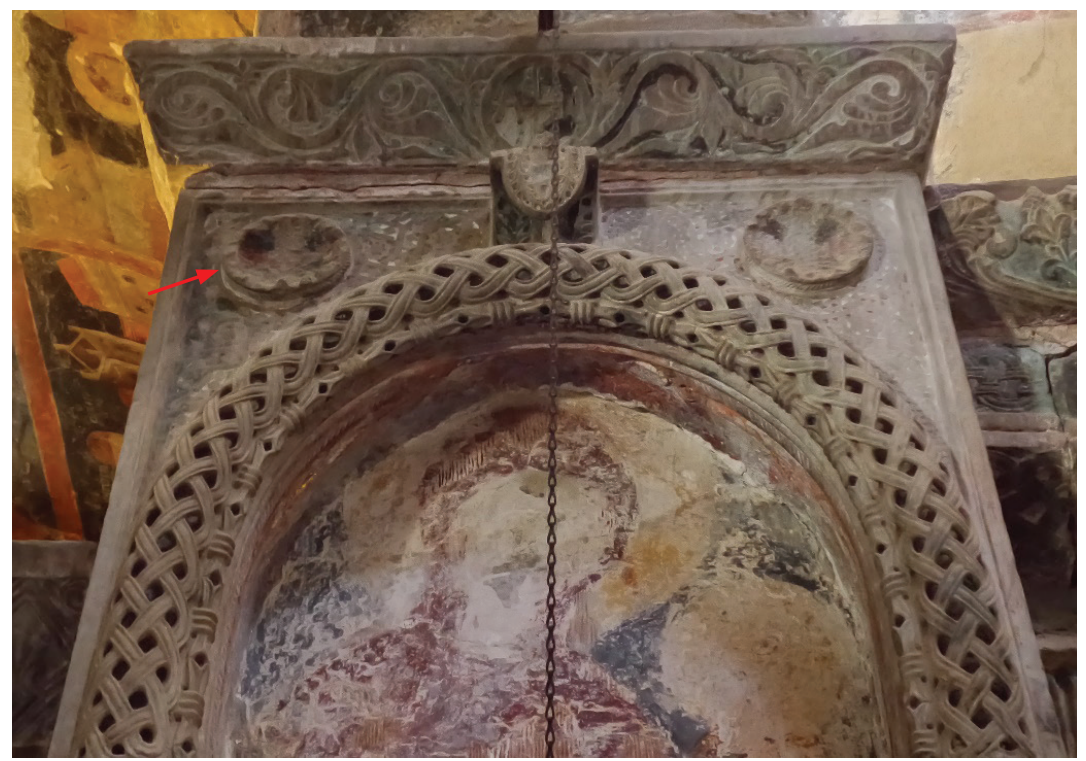

G.10. Mistras Aziz Demetrios Kilisesi, 1261 sonrası, templon kuzey proskynetria ve kaboşonlar (Z. Boleken arşivi, 2019) 


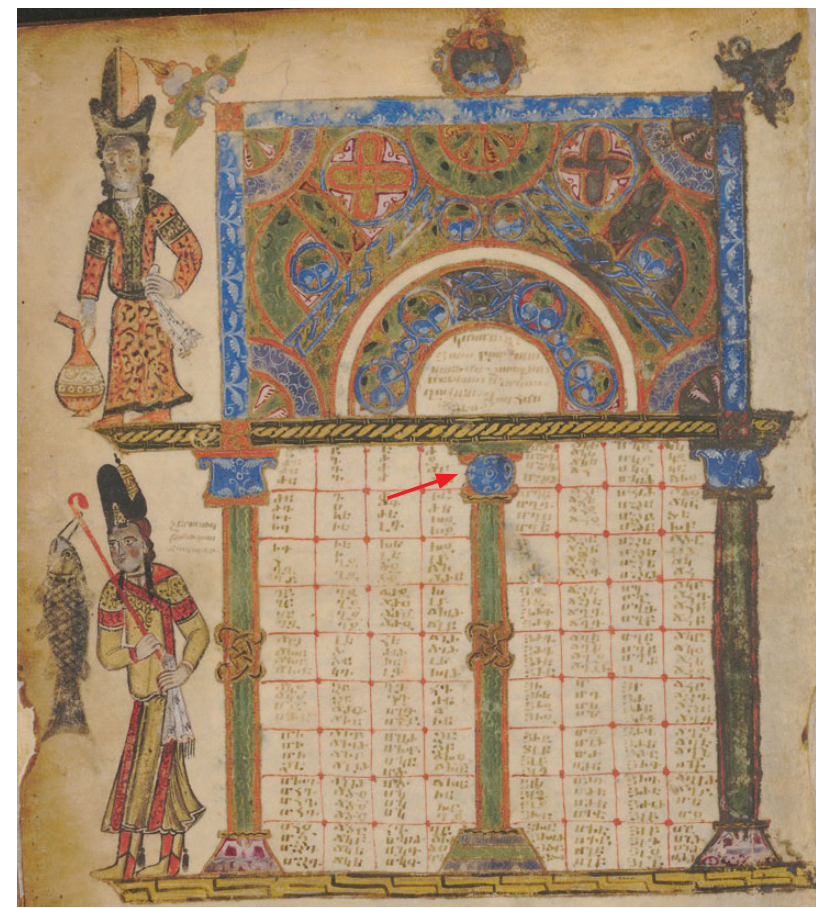

G.11. Kanon Tablosu, Haghpat İncili, 1211, fol 8v, (A. Eastmond, Tamata’s World, P1.17)

Bezirana Kilisesi'nde (13. yüzyıl sonu - 14. yüzyıl başı) doğu cephede kemer üstü dolgusu olan bölgede aynı zamanda ünik özellik gösteren disk motifleri yer almaktadır. Doğu duvarın kuzey tarafında bulunan kırmızı disk güneşi (G. 2), güney tarafında bulunan gri-mavi renklerdeki disk ise $a y 1^{19}$ (G. 1) anımsatmaktadır. Kapadokyalı Kilise Babalarından Aziz Basileios'un vaazlarında bu konu üzerine "Güneș ve Ay, saflık, temizlik ve ruhani 1şık gibi bazı kavramları başarmak için araçtır ve yaratıcının büyük bilgeliğine doğru hareket etmeleri için insanlara yardım eder" ifadelerini kullandığ 1 bilinmektedir. ${ }^{20}$ Ayrıca, bu disk motifleri üç merkezden ${ }^{21}$ oluşmakta ve iç kısımlarındaki farklı renk tonlarında dönen çizgiler ile hareket etmekte veya dönmekte olan bir motif izlenimi yaratmaktadır. Disklerin üç merkezli olmaları kutsal üçlemeye bir gönderme ${ }^{22}$ olarak düşünülebilir, hatta disklerin yüksek konumlu olarak resme-

19 Ek olarak, güneş ve ay tasvirleri, Hristiyan ikonografisinde İsa'nın ölümü sahnelerinde göğe yükseliş ve son yargıda yeryüzüne inişte olduğu gibi sıkça işlenmiştir. Detaylı bilgi için bk. Maurice Didron, The History of Christian Art in The Middle Ages I, çev. E. J. Millington (London: Henry G. Bohn, York Street, Covent Garden, 1851), 86-87.

20 Anne Karahan, "The Image of God in Byzantine Cappadocia and the Issue of Supreme Transcendence," 107.

21 Daire motifinin dış çizgileri yaratılan her şeyin sınırını; merkeze doğru giden çizgileri yollar ya da insan yaşamını; merkez çizgileri ise Tanrıyı temsil etmektedir. Detaylı bilgi için bk. Jasmina S. Ćirić, "Solar Discs in the Architecture of Byzantine Constantinople: Examples and Parallels," International Symposium in Honour of Emeritus Proffesor George Velenis, ed. Flora Karagianni, (Thessaloniki, 2020) (forthcoming), 13.

22 Leshcheva Yana Igorevna, "Whirling Disc" in the Byzantine Iconography. Search for Meaning," Science Journal of Volgograd State University. History. Area Studies. International Relations 19/3 (2014), 44; Panayotis St. Katsafados, "New Epigraphıc Evidence From Mani The Kaphiona Epigrams," 42. 
dilmeleri23 ilahi karakterleri açısından bizlere daha kesin sonuçlar vermektedir. Hem konu üzerine daha önce çalışmalar yapan bazı araştırmacılar hem de Bezirana Kilisesi üzerine incelemelerde bulunan J. Levy, bu motifleri, Antik Çağlardan beri tanrıların ve İmparatorların imgeleriyle ilişkilendirilen sonsuz güç ve evrenin antik sembolleri olarak değerlendirmekte ayrıca İsa'nın çarmıha gerilmesi sonucu ölümü ve efharistia ayini ile ilişkili olabileceklerini düşünmektedir. ${ }^{24}$

Dönen disk motiflerinin farklı bir varyasyonu olarak Kızılçukur Yohakim ve Anna Kilisesi (9. yüzy1l) (G.12) ve Ihlara Y1lanlı Kilise'de (9-10. yüzyıl) (G.13, G. 14) çarkıfelek motifleri ile karşılaşmaktayız. Dönen disk motiflerinde olduğu gibi bu motiflerin de aynı teolojik ve apotropaik etkiye sahip oldukları da düşünülebilir. Nitekim Sırp araştırmacı J. Ćirić, motifin Bizans mimarisindeki örneklerinin de bu anlamları taşıdığııı öne sürmektedir. ${ }^{25}$

Tüm bu bilgiler de göz önünde bulundurulduğunda Doğu Hristiyanlığında ilahi 1şık ve kutsal enerjinin önemli bir gerçekliliğe sahip olduğu anlaşılmaktadır. Dolayısıyla bu motifler, aslında kutsal enerjinin simgeleri ve mabetlerin içerisinde kutsal enerjiyi yayan birer araç olarak da düşünülebilir.

23 Konu üzerine yapılan güncel çalışmalar, Bizans anıtsal resim sanatında görsel ve materyal arasındaki etkileşimin baninin Bizans kimliğini (soysal sınıfını) yansıtması bakımından da önem taşıdığını göstermektedir. Detaylı bilgi için bk. Besim Tolga Uyar, "Carving, Painting, and Inscribing Sacred Space in Late Byzantium Bezirana Kilisesi Rediscovered (Peristrema-Cappadocia)," Architecture and Visual Culture in the Late Antique and Medieval Mediterranean, ed. Vasileios Marinis, Amy Papalexandrou ve Jordan Pickett, (Turnhout: Brepols Publishers, 2021), 211. Ayrıca Bizans sanatında görsel malzeme ve materyal arasındaki etkileşim ve birlikte işlev görmeleri hakkında bk. Antje, Bosselman Ruickbie, "The Symbolism of Byzantine Gemstones: Written Sources, Objects and Sympathetic Magic in Byzantium," Gemstones in the First Millennium Ad. Mines, Trade, Workshops and Symbolism, Römisch-Germanisches Zentralmuseum Tagungen Band 30, ed. Alexandra Hilgner, Susanne Greiff ve Dieter Quast, (Mainz: Verlag des Römisch-Germanischen Zentralmuseums, 2017), 300-301.

24 Levy, "Bezirana Kilisesi (Cappadoce). Un Exceptionnel Decor Paleologue en teres de Rum. Nouveau temoigage sur les relations entre Byzance et Le Sultanat," 125. Ayrıca araştırmacılardan T. Uyar, J. Levy'nin bu görüşünü desteklemektedir. Bk. Besim Tolga Uyar, "Carving, Painting, and Inscribing Sacred Space in Late Byzantium Bezirana Kilisesi Rediscovered (Peristrema-Cappadocia)," 209.

25 Bk. Ćirić, "Solar Discs in the Architecture of Byzantine Constantinople: Examples and Parallels," 14. Ayrıca, Araştırmacı Anne Karahan, bordürleri, altın, gümüş, değerli taş, inci, daire (disk) gibi motifleri ve kutsal alana kubbe, pencere ve delikli duvarlar vasıtası ile süzülen ışı̆̆ı, inananlara Tanrının yüce varlığını ve kutsallığını düşünmede yardımcı olan apofatik (negatif teoloji) araçlar olarak değerlendirmektedir. Detaylı bilgi için bk. Anne Karahan, "Beauty in the Eyes of God. Byzantine Aesthetics and Basil of Caesarea," Byzantion 82 (2012), 210. 


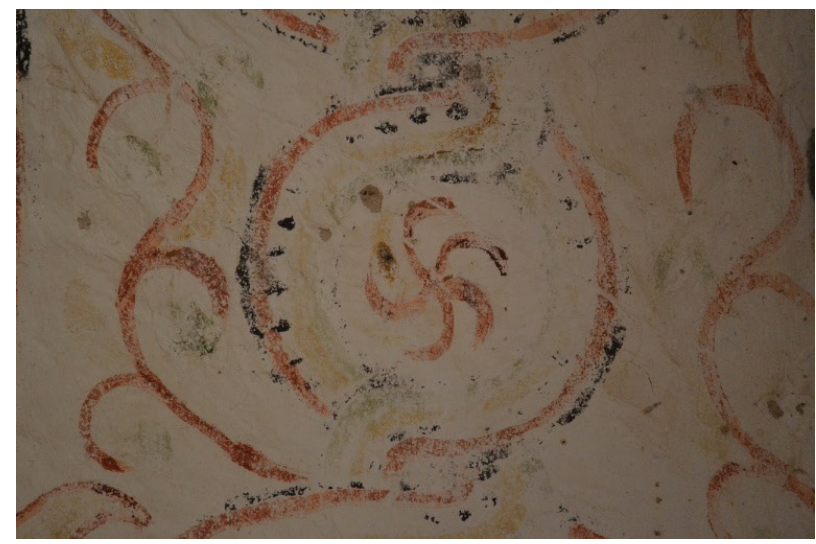

G.12. Kızılçukur Yohakim ve Anna Kilisesi, 9. yüzyıl, güney şapel beşik tonoz yüzeyi (M. Kaya arşivi, 2016)

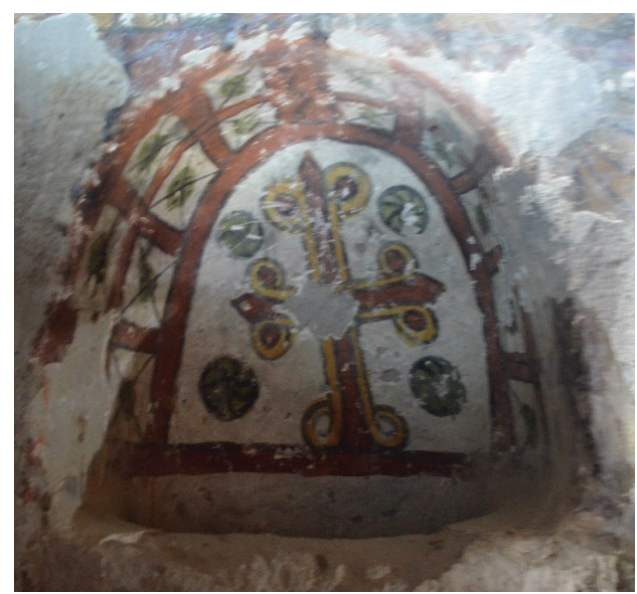

G.13. Ihlara Yılanlı Kilise 9-10. yüzyıl, güney haç kolu niş iç yüzeyi (M. Kaya arşivi, 2016)

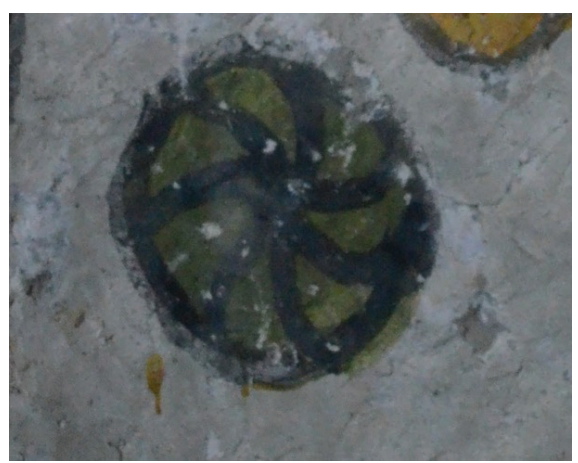

G.14. Ihlara Yılanlı Kilise 9-10. yüzyıl, güney haç kolu niş iç yüzeyi, çarkıfelek motif detayı (M. Kaya arşivi, 2016) 
Yine Bezirana Kilisesinin apsis kemerinin yanlarındaki dönen disklerle karş1lık11 yerleştirilmiş olan ve kutsal enerjinin bir başka simgesi olarak karşımıza çıkan motif; sekiz kollu rozettir ${ }^{26}$ (G.15). Bu şekilde disk motifler ile karşl1ıklı kullanım Bizans sanatında Mani Hagioi Theodoroi Kilisesinde de (1263-70) görülebilmektedir. Araştırmacılar, bu durumun disk motifleri ile sekiz kollu rozet motiflerinin teofanik ve apotropaik anlamlarının yakın olmasına bir atıf olabileceğini düşünmektedirler. ${ }^{27}$ Motif, hem Bizans minyatür sanatında hem de duvar resimlerinde 13. yüzyılın ikinci yarısında ve 14. yüzyılda sıkça görülmektedir. ${ }^{28} \mathrm{Bu}$ motifin bölgedeki diğer örneklerine Gülşehir Yüksekli Kilise (geç 13. yüzyıl) (G.16) ve Ihlara Ağaçaltı Kilisesi'nde (9. yüzy1l) (G.17) rastlamaktayız. Motif, Yüksekli Kilise naosunun kuzey ve güney duvarlarının kemer boşluklarında karşılıklı olarak ikişer adet resmedilmiştir. Ayrıca altı kollu ya da çok kollu rozetler de bölgede karşılaştığımız diğer rozet motifin varyasyonlarıdır.

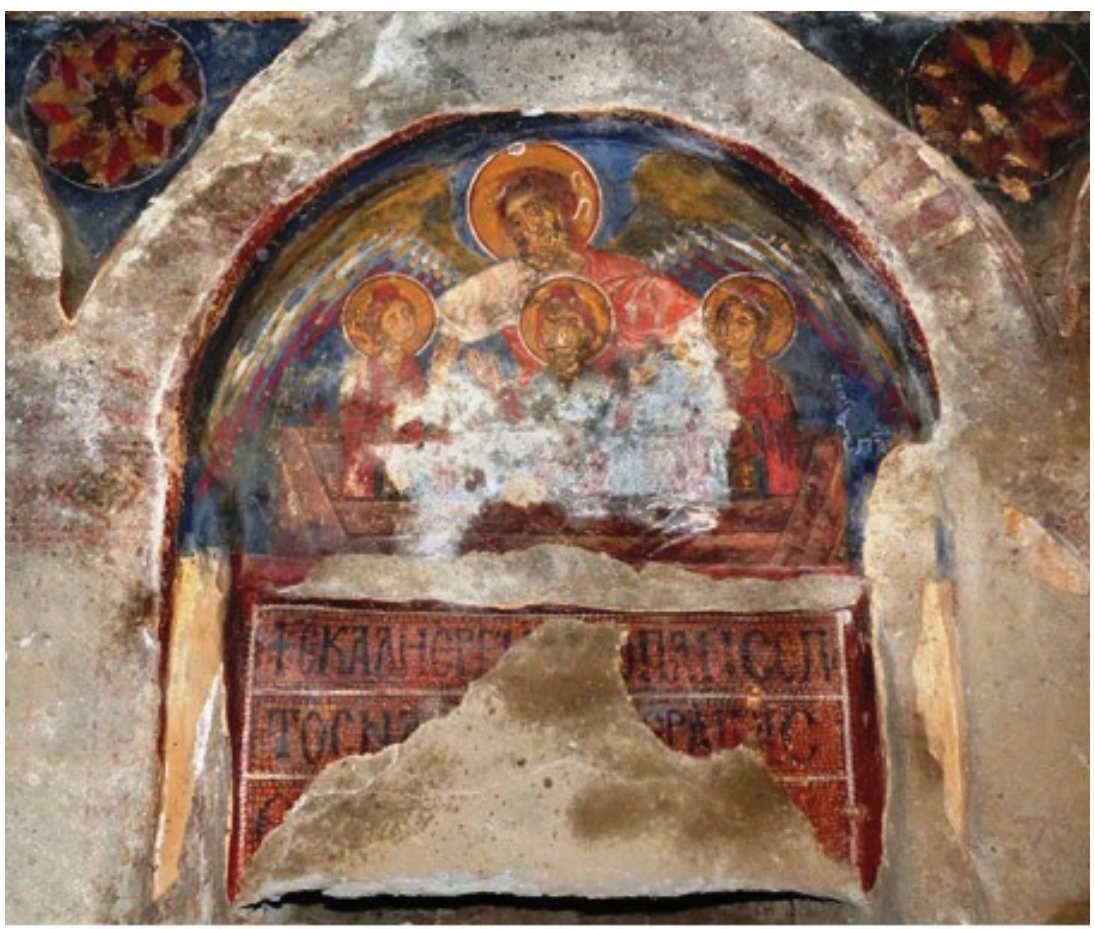

G.15. Bezirana Kilisesi, geç 13. yüzyıl - erken 14. yüzyıl, batı duvar, sekiz kollu rozet motifleri (J. Levy, Bezirana Kilisesi (Cappadoce), 115)

26 Bu motif, Sanat tarihi terminolojisine "cocardes en accordéon (Üç boyutlu sekiz kollu rozet)" olarak girmiştir. Detaylı bilgi için bk. Levy, "Bezirana Kilisesi (Cappadoce). Un Exceptionnel Decor Paleologue en teres de Rum. Nouveau temoigage sur les relations entre Byzance et Le Sultanat," 126-127.

27 Levy, "Bezirana Kilisesi (Cappadoce). Un Exceptionnel Decor Paleologue en teres de Rum. Nouveau temoigage sur les relations entre Byzance et Le Sultanat," 127.

28 Levy, "Bezirana Kilisesi (Cappadoce). Un Exceptionnel Decor Paleologue en teres de Rum. Nouveau temoigage sur les relations entre Byzance et Le Sultanat," 127. 


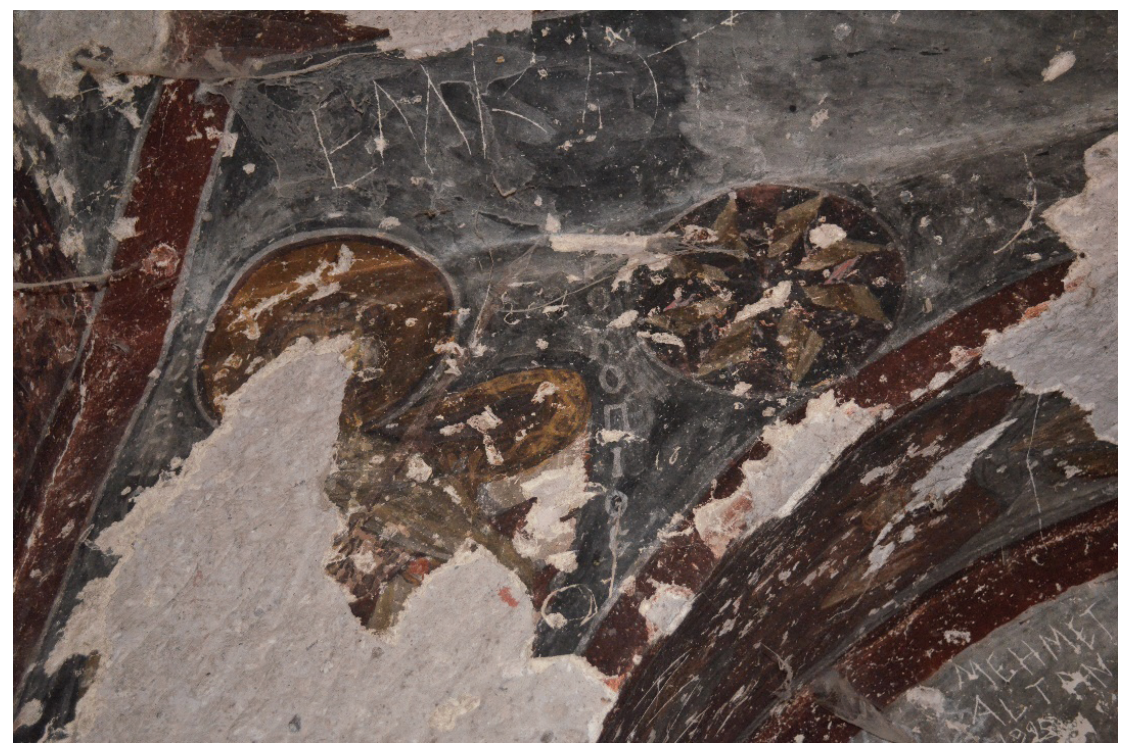

G.16. Gülşehir Yüksekli Kilise, geç 13. yüzyıl, kuzey duvar, sekiz kollu rozet (M. Kaya arşivi, 2017)

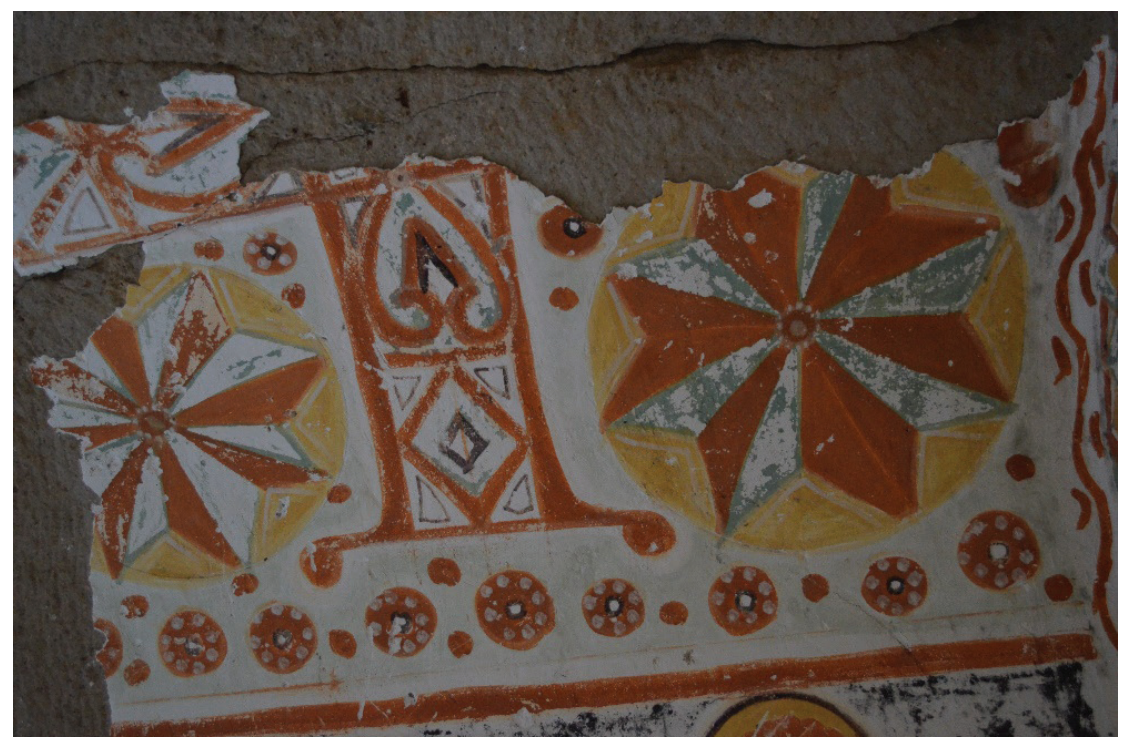

G.17. Ihlara Ağaçaltı Kilisesi, 9. yüzyıl, güney haç kolu, beşik tonoz, sekiz kollu rozet (M. Kaya arşivi, 2016) 
Sütunlu kilise grubunda ${ }^{29}$ bulunan Karanlık Kilise (11. yüzy1l) (G. 18), Elmalı Kilise (11. yüzyı1) (G. 19) ve Çarıklı Kilise'nin (11. yüzyıl) (G. 20) motif repertuvarında bitkisel motifler kategorisinden akanthus motifi resmedilmiştir. Hristiyanlık, bu bitkiye esasen küçük dikenlerinden kaynaklı olarak İncil metinleri ve Kilise Babalarının açıklamaları doğrultusunda günahla ilgili acıya ve pişmanlık ile ilgili insan ıstırabına sembolik bir anlam yüklemektedir. ${ }^{30}$ Yukarıda bahsettiğimiz üç kilisede, Kapadokya bölgesinde diğer kiliselerden farklı olarak akanthus motifleri form açısından sarmal özelliktedir ve geniş yüzeyleri kaplamaktadır. Bu motiflerin özellikle yapıların üst örtü birimlerinde sanatçılar tarafından kullanımlarının tercih edildiği göze çarpar. $\mathrm{Bu}$ anlamda, ikonografik sahnelere ayrılan alanlar haricinde, motifin üst örtü birimlerinde kullanımının sanatçı tarafından tercih edilmiş olması, motifin semantik işlevi ile mimari arasında bir ilişki var mıydı? sorusunu aklımıza getirmektedir. Ancak her şeyden önce sanatçının geniş yüzeyi en uygun akanthus sarmalı ile bezeme düşüncesinin ve bu geniş alanları göz alıcı şekilde (estetik) dekore etme isteğinin olduğu da anlaşılmaktadır.

29 Sütunlu kilise grubunda bulunan eserlerden ilk hangisinin ve daha sonra hangilerinin yapıldığı ve yapım tarihleri hakkında araştırmacılar farklı savlara sahiptir. Bu konu hakkında araştırmacı görüşleri ve sütunlu kilise ve bu grup yapılarında çalışan atölye grubu ile ilgili detaylı bilgi için bk. Guillaume D. Jerphanion, Une Nouvelle Province de l'art Byzantin: Les Eglises Rupestres de Cappadocia 1/2 (Paris: Librairie Orientaliste Paul Geuthner, 1932), 378-392; Marcell Restle, Byzantine Wall Painting $n$ Asia Minor 1 (Shannon: Irish University Press, 1967), 57-58; Ann Wharton Epstein, "Rock-Cut Churches Chapels in Göreme Valley Cappadocia: The Yılanlı Group and The Column Churches," Cahiers Archéologiques 24 (1975), 115-135; Rainer Warland, Byzantinisches Kappadokien (Darmstadt / Mainz: Verlag Philipp von Zabern, 2013), 8499; Robert Ousterhout, Visualizing Community, Material Culture And Settlement in Byzantine Cappadocia (Washington: Dumbarton Oaks Research Library And Collection, 2017), 187-188.

30 Ana Maria Quinones, Symboles Végétaux: La Flore Sculptée Dans L'art Médiéval (Paris: Desclée de Brouwer, 1995), 70 . 


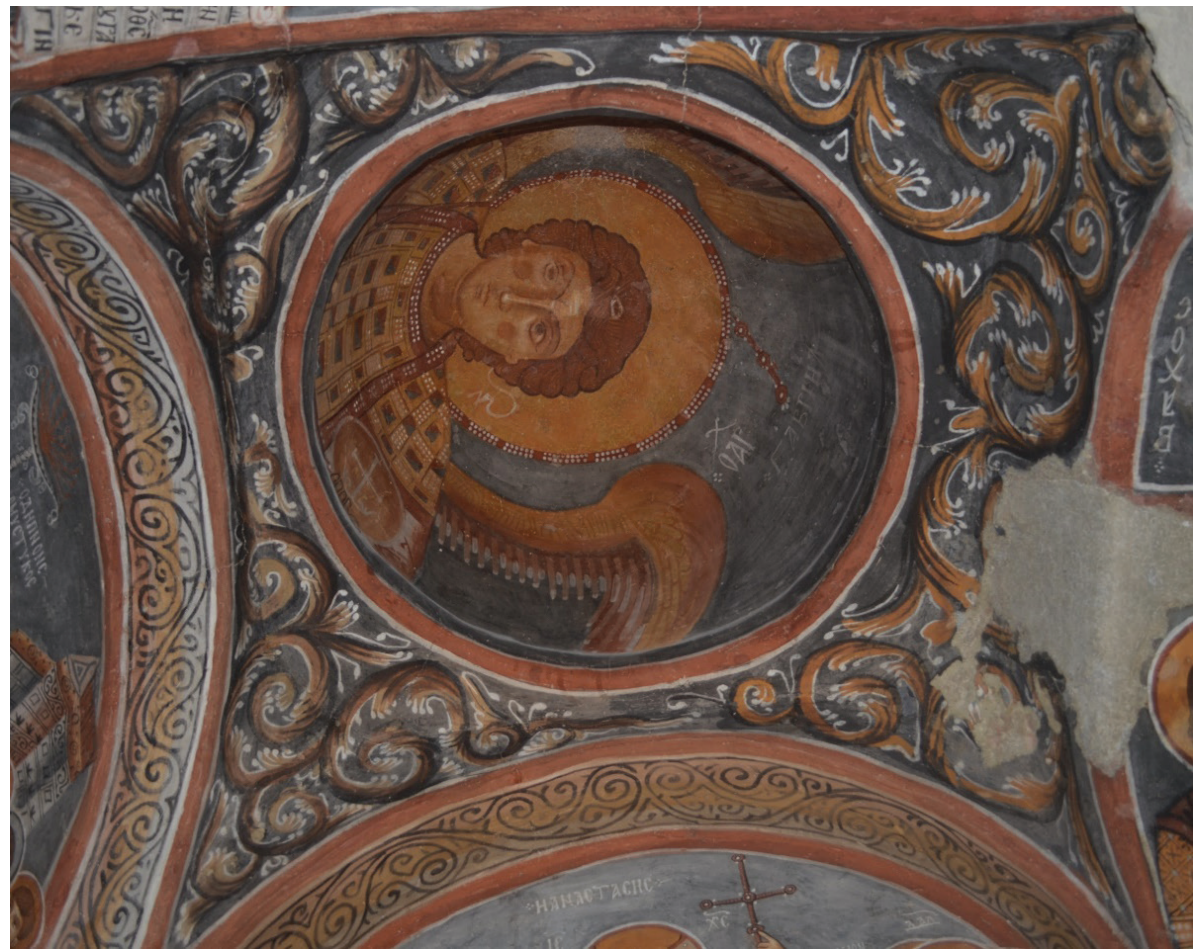

G.18. Göreme Karanlık Kilise, 11. yüzyıl, sarmal akanthus motifleri (M. Kaya arşivi, 2016)

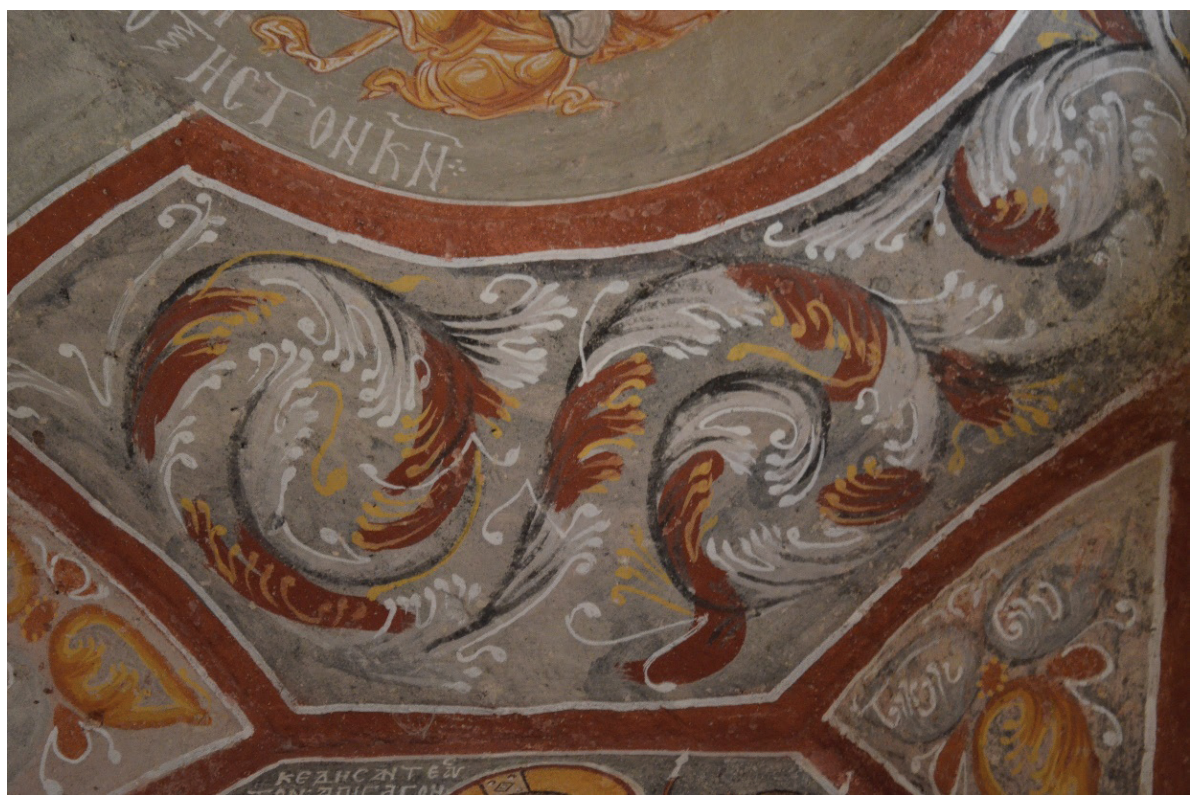

G.19. Göreme Elmalı Kilise, 11. yüzyıl, sarmal akanthus motifleri (M. Kaya arşivi, 2016) 


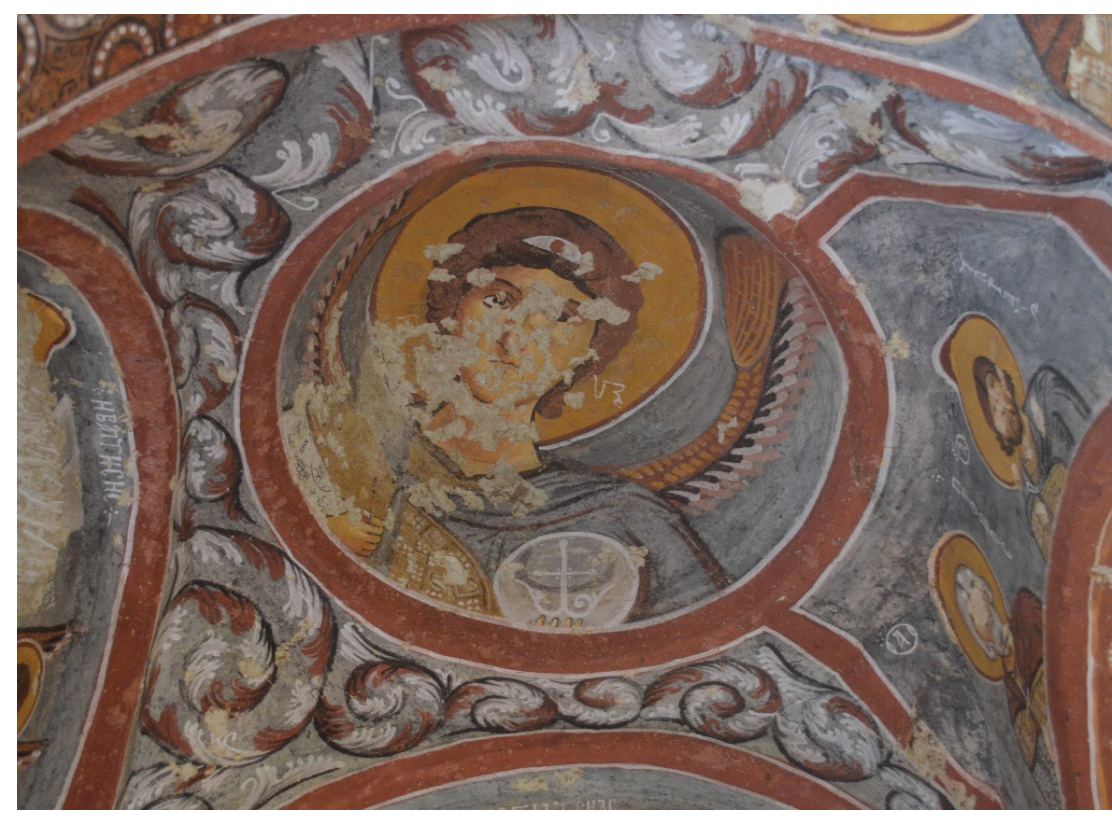

G.20. Göreme Çarıklı Kilise, 11. yüzyıl, sarmal akanthus motifleri (M. Kaya arşivi, 2016)

İnci (mücevher-değerli taş) motifi, Bizans sanatında el yazması eserlerde bordür içerisinde sınırlı olarak uygulanmışken özellikle kitap kapaklarında ve mozaik sanatında yoğun olarak kullanılmıştır. Araştırmacılar bu motifin klasik bir boncuk veya makara motifinden dejenere olarak Bizans sanatına girdiğinin, ayrıca oyma eserlerden mücevher eserlere de geçiş yaptığının üzerinde durmaktadırlar. ${ }^{31}$

İnci motifi, Kapadokya bölgesinde 9. yüzyıldan başlayarak orta ve geç Bizans dönemine tarihlendirilen duvar resimlerinde karşımıza çıkmaktadır. Bölgedeki örneklere bakıldığında; motifin kimi zaman bordür içerisinde (G. 21) kimi zamansa bir başka motifle kombine (G. 22) olarak kullanıldığı anlaşılmaktadır. Sembolik olarak, inci motifi kutsal üçlemede İsa'nın dünyanın nuru olması ve Tanrı'nın ilahi ışı̆̆g ile ilişkilendirmektedir. ${ }^{32}$ Ayrıca, inci motiflerinin daire hâlinde olması sonsuz yaşama gönderme ${ }^{33}$ ve İmparator taçlarında görülmesi ise, erdem göstergesi olarak değerlendirilmektedir.

31 Bk. M. Alison Frantz, "Byzantine Illuminated Ornament: A Study in Chronology,” Art Bulletin 16/1 (1934), 66. Ayrıca Frantz, motifin Bizans sanatında en erken kullanımının Roma'da bulunan 4. yüzyıl tarihli Santa Pudenziana Bazilikası'nın apsis mozaiğinde görüldüğünü belirtmektedir. Bk. Frantz, "Byzantine Illuminated Ornament: A Study in Chronology," 65. Motifin, erken Hristiyanlık döneminde gerçek bir mücevher eserde kullanımı ise İmparator II. Justinianos'a (MS 565-578) ait haç üzerinde yer almaktadır. Bk. Ormonde Maddock Dalton, Byzantine Art and Archaeology (Oxford: Oxford At The Calarendon Press, 1911), 548.

32 Bk. Anne Karahan, "The Image of God in Byzantine Cappadocia and the Issue of Supreme Transcendence," 105-106.

33 Karahan, "The Image of God in Byzantine Cappadocia and the Issue of Supreme Transcendence,” 105. 


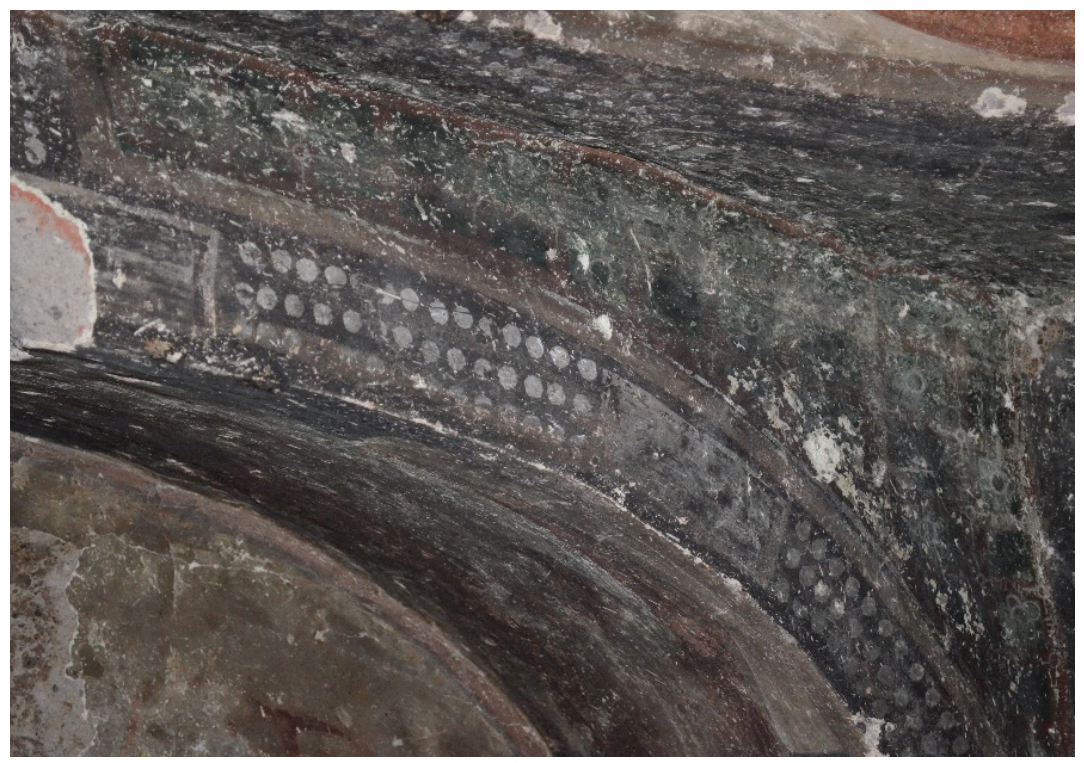

G.21. Belisırma Bahattin Samanlığı Kilisesi, 10-11. yüzyıl, kuzey duvar niş kemeri, inci bordürler (M. Kaya arşivi, 2016)

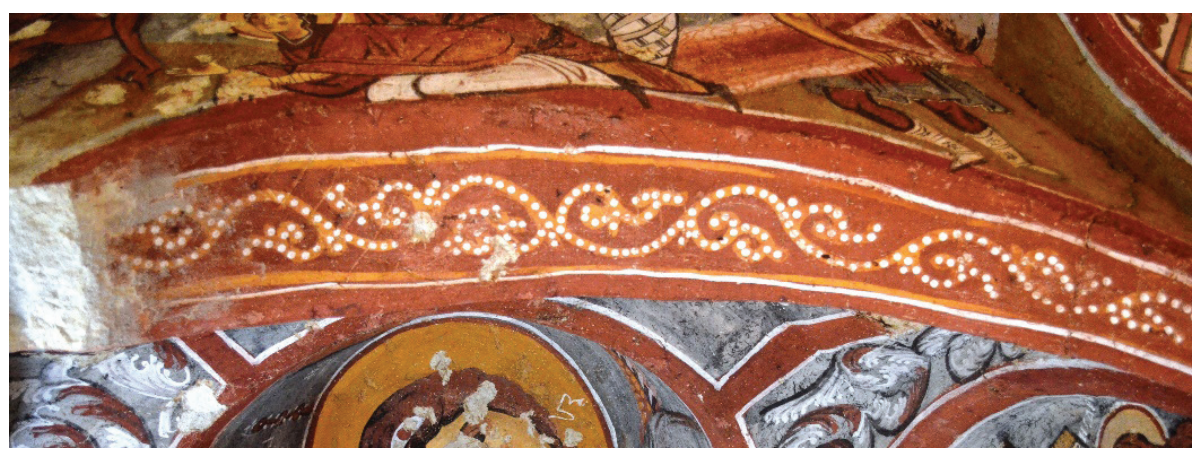

G.22. Göreme Çarıklı Kilise, 11. yüzyıl, güneydoğu köşe mekan kemeri, inci motifinin sarmal palmet motifi ile kombine kullanımı (M. Kaya arşivi, 2016)

Tanrının kutsal 1şığı ile ilişki kurabileceğimiz bir diğer motif ise üç boyutlu zikzak motifidir (G. 23, G. 24). Bu bir şerit bezemesidir; orta Bizans anıtsal duvar resimlerinde, el yazmalarında ve 13 - 14. yüzyıl ikonalarında standart özelliklerden biri haline gelmiştir. ${ }^{34}$

Son zamanlarında yaptığı bir çalışmada S. Curcic, bu dekorasyona özel önem vermiştir: Bu motifi "üç boyutlu katlanmış plaka” ve İlahi ışığın sembolik anlamı olarak

34 Detaylı bilgi için bk. Slobodan Curcic. "Divine Light: Constructing the Immaterial in Byzantine Art and Architecture," Architecture of Sacred, ed. Bonna D. Wescoat ve Robert G. Ousterhout (New York: Cambridge University Press, 2012), 314. 
tanımlamaktadır. ${ }^{35}$ S. Curcic ayrıca, Ermeni el yazmalarında motifin egzotik bitkiler ve hayvanlar ile birlikte kullanımının sadece kutsal ışı̆̆ın sembolizmi ile ilişkili olmadığına aynı zamanda yaratıcı bir biçimde cenneti de sembolize etmiş olabileceğine dikkat çekmektedir. ${ }^{36}$

$\mathrm{Bu}$ süslemelerin klasik sanattan geldiği anlaşılabilir. Nitekim, buna örnek olarak bugün Hatay Arkeoloji Müzesinde bulunan 3. yüzy1ldan kalma zemin mozaiği (G. 25) ve 8. yüzyıldan kalma, Kasr Amra'daki Emevi Sarayı kubbe kasnağ yüzeyinde ${ }^{37}$ (723-743) yer alan üç boyutlu zikzak motifleri gösterebilir. ${ }^{38}$

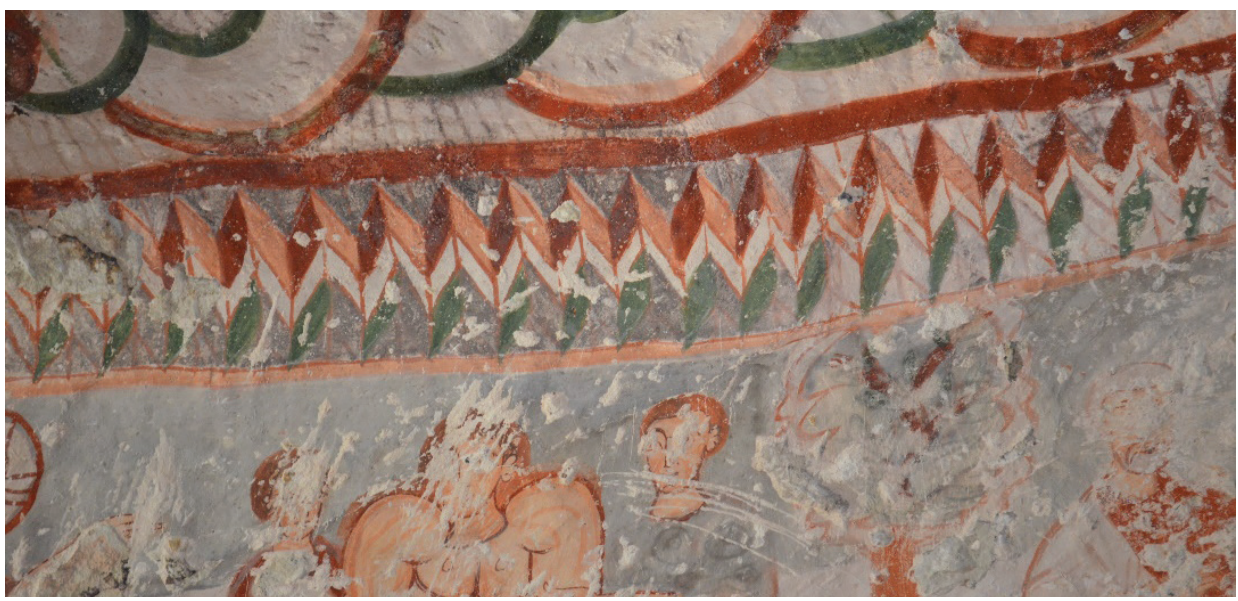

G.23. Mustafapaşa Pancarlık Kilisesi, geç 9-10. yüzyıl, nef, güney duvar, üç boyutlu zikzak motifi (M. Kaya arşivi, 2016)

35 Curcic, "Divine Light: Constructing the Immaterial in Byzantine Art and Architecture," 314. Ayrıca üç boyutlu zikzak motifinin Türk sanatındaki yayılımını inceleyen M. Baha Tanman, Korkuteli Alaeddin Cami (14 ya da 15. yüzyıl) üzerine araştırmalar yapmış ve yapının taç kapısında bulunan üç boyutlu formadaki zikzak kemerin Haçlı Seferleri’ni izleyen yıllarda, Filistin yöresinde, günümüzde kimi araştırmacıların Haçlı Eyyubi olarak isimlendirdiği melez üslubun bünyesinde doğmuş olduğuna ve daha sonra muhtemelen Filistin-Suriye kuşağından gelen ustalar aracılığıyla Mısır, Kıbrıs, Rodos, Anadolu ve Rumeli'yi kapsayan geniş bir coğrafyaya yayılmış olduğuna değinmektedir. Tanman ayrıca, Filistin'de, Yubna köyünde Memluk dönemine ait (1274) Ebu Hureyre Meşhedi'nin giriş revağının ortasındaki kemer, Kıbrıs'ın Lusignan Dönemi'ne ait yapılarından Bellapais Manastırı'nda, 1324-1329 arasına tarihlenen yemekhanenin kapısındaki kemer, Osmanlı coğrafyasından da Bursa Ulu Cami'nin kuzey cephesindeki bazı pencerelerin hafifletme kemerlerinin bu durumu örneklediğini belirtmektedir. Detaylı bilgi için bk. Mehmet Baha Tanman, "Beylikler Dönemi Anadolu Türk Mimarlığının İncelenmemiş Bir Ürünü: "Korkuteli Alaeddin Camii," Beylikler Dönemi Kültür ve Sanatı Sempozyum Bildiri Kitabı (İstanbul: Sanat Tarihi Derneği Yayınları, 2014), 166-167.

36 Curcic, "Divine Light: Constructing the Immaterial in Byzantine Art and Architecture," 319.

37 Kasr Amra'daki Emevi Sarayı kubbe kasnağı yüzeyinde bulunan üç boyutlu zikzak motifi için bk. "Zodiac painting on caldarium dome" Molon, erişim 14 Ocak 2021,

https://www.molon.de/galleries/Jordan/Castles/Amra/img.php?pic=7

38 Bu motif aynı zamanda 2017 yılında Berlin'de düzenlenen IV. Forum Kunst Des Mittelalters Sempozyumunda, tarafimizca sunulan "Is the Ornament a Space of Liberty or of the Subordinate? The Case of Cappadocian Frescoes" başlıklı bildiride detaylı olarak değerlendirilmiştir. 


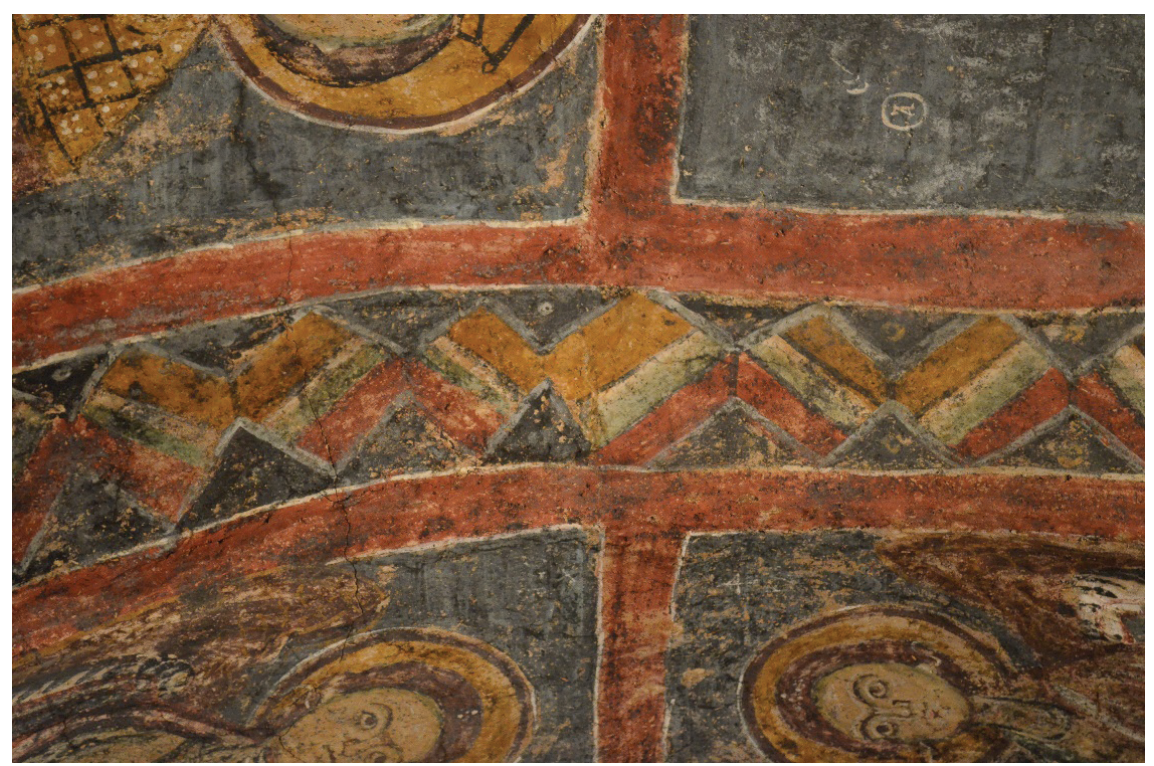

G.24. Tatlarin 1 Nolu Kilise, 13. yüzyıl, kuzey nef apsis kemer detayı, üç boyutlu zikzak motifi (M. Kaya arşivi, 2016)

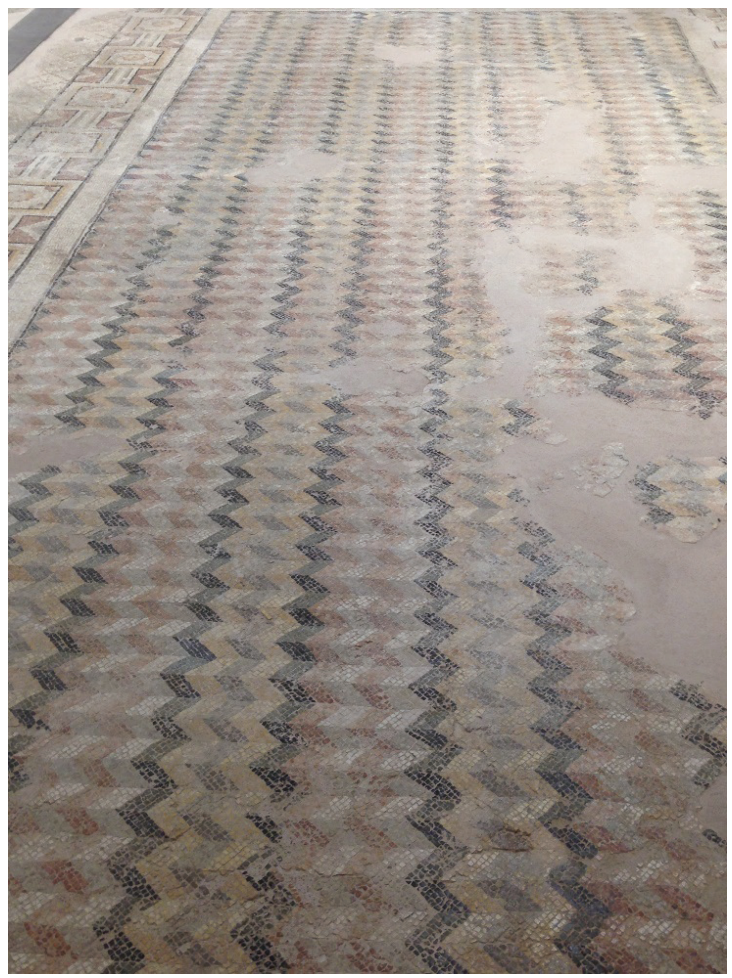

G.25. Hatay Arkeoloji Müzesi, Roma Döşeme Mozaiği, 3. yüzyıl, üç boyutlu zikzak motifleri (M. Kaya arşivi, 2015) 
Geometrik desenler kategorisinden Antik Çağ'daki kullanımlarından beri apotropa$i k$ etkisi olduğu bilinen antrolak motifi, ${ }^{39}$ Kapadokya bölgesi duvar resimlerinde arkaik dönem bezeme unsuru olarak karşımıza çıkmaktadır. Özellikle, 9. ve 10. yüzyıl tarih aralığında yoğun şekilde kullanıldığ 1 anlaşılmaktadır.

Bölgede karşılaşılan apotropaik etkili ve kutsal anlam taşıyan motiflerde farklı renklerin kullanılması da üstlendikleri anlamları pekiştirmektedir. Hristiyan sanatında mavi, cenneti, Tanrısal mekân olan gökyüzünü, Tanrı’nın doğa üstünlüğünü ve üçlü tabiat (teslis) dogmasını; kızıl kahverengi ya da kırmızı, kan ve insanlığı, ateş olarak da Tanrısal enerjiyi; beyaz, kutsallık, saflık ve aydınlanmışlığı; sarı, kutsallığı, zenginliği ve gücü; siyah, üzüntü ve kederi; yeşil ise canlanmayı simgelemektedir. Mavi, kızıl kahverengi veya kırmızı, sarı renkler kombine kullanıldıklarında ise sırası ile baba, oğul ve kutsal ruhu temsil etmektedir. ${ }^{40}$

\section{Sonuç}

Kapadokya bölgesi duvar resimlerinde kutsal anlam taşıan ve apotropaik etkili olduğu düşünülen motiflerden bazılarının değerlendirildiği bu çalışmada; bölge duvar resimlerinde çalışan sanatçıların Helenistik geleneklere bağlı ve Hristiyan bilgilerine sahip çoğunluğu yerli ustalar olduğu görülmektedir. Bu sanatçıların motifleri resmederken Kutsal Kitap ve Kapadokyalı Kilise Babalarının doktrinleri doğrultusunda içerdikleri anlam (sembolik mesaj), estetik değer ve mimari çerçevesinde motifin konumlanmaları gereken yükseklik ya da alanı da göz önünde bulundurdukları anlaşılmaktadır. İncelenen motiflerin çoğunlukla ilahi 1şık ve enerji, sonsuz yaşam, cennet, İsa ve efkharistia ayini ile ilgili olarak izleyiciye sembolik mesajlar verdiği ve Bizans estetik anlayışı ile de uyum içerisinde olmalarına özen gösterildiği düşünülmektedir. $\mathrm{Bu}$ anlamda, bölgede orta ve geç Bizans dönemi duvar resimlerinde bazı motiflere kutsal anlam ve apotropaik anlam yüklendiği ve bu motiflerin güçlü bir yönlendirici görevi gördükleri muhtemeldir. Ortaçağ Kapadokyası'nda kilise içerisinde yanan kandil ışıklarının da etkisi ile bu motiflerin izleyici açısından etkileyici bulundukları tahmin edilmekte. Yapılan çalışmalar, anikonik motiflerin sadece bir bordür bezemesi olmadığını, Kapadokya örneklerinden yola çıkarak Bizans anıtsal resim sanatında figürlü ve figürsüz resmin aslında birbirinden ayrılamayacak derecede iç içe geçmiş olduğunu ve kilise içerisinde bütünsel bir anlayış yaratmak için birlikte işlev gördüğünü göstermektedir. Kapadokya bölgesi duvar resimleri, motif repertuvarı bakımından kültürel çeşitliliği ve Ortaçağ Anadolusu'ndaki sanatsal etkileşimi yansıtması bakımından da ayrıca önem taşımaktadır.

39 Bu motifin özellikle kötü niyetli bakışlara karşı göz alıcı ve kafa karıştırıcı özellikleri nedeni ile koruyucu gücü olduğu bilinmektedir. Antrolak motifinin apotropaik etkisi hakkında detaylı bilgi için bk. James Trilling. The Language of Ornament (New York: Thames \& Hudson Ltd, 2001), 134-135.

40 Detaylı bilgi için bk. Asnu Bilban Yalçın, "Bizans Estetiğine Giriş,” Değişen Tarihsel Süreçler Değişen Kavramlar, ed. Kıymet Giray (Ankara: Ankara Üniversitesi Basımevi, 2008), 60; Anne Karahan, "The Image of God in Byzantine Cappadocia and the Issue of Supreme Transcendence," 110. 
Hakem Değerlendirmesi: Dış bağımsız.

Çıkar Çatışması: Yazar çıkar çatışması bildirmemiştir.

Finansal destek: Bu çalışma, 21619 Nolu Doktora Tez Projesi kapsamında İstanbul Üniversitesi BAP Birimi tarafindan finansal açıdan desteklenmiştir.

Peer-review: Externally peer-reviewed.

Conflict of Interest: The author has no conflict of interest to declare.

Grant Support: This study was financially supported by the Scientific Research Projects Coordination Unit of Istanbul University within the scope of the doctorate thesis project number 21619 .

\section{Kaynakça/References}

Aslanapa, Oktay. Turkish Art and Architecture. Ankara: Atatürk Kültür Merkezi Yayınları, 2004.

Bosselman-Ruickbie, Antje. "The Symbolism of Byzantine Gemstones: Written Sources, Objects and Sympathetic Magic in Byzantium," Gemstones in the First Millennium Ad. Mines, Trade, Workshops and Symbolism, Römisch-Germanisches Zentralmuseum Tagungen, Band 30. Ed. Alexandra Hilgner, Susanne Greiff ve Dieter Quast. Mainz: Verlag des Römisch-Germanischen Zentralmuseums, 2017, 293-306.

Curcic, Slobodan. "Divine Light: Constructing the Immaterial in Byzantine Art and Architecture." Architecture of Sacred, Ed. Bonna D. Wescoat ve Robert G. Ousterhout. New York: Cambridge University Press, 2012, 307-338.

Dalton, Ormonde Maddock. Byzantine Art and Archaeology. Oxford: Oxford At The Calarendon Press, 1911.

Eastmond, Antony. Tamata's World The Life and Encounters of a Medieval Noblewoman from the Middle East to Mongolia. Cambridge: Cambridge University Press, 2017.

Epstein, Ann Wharton. "Rock-Cut Churches Chapels in Göreme Valley Cappadocia: The Y1lanlı Group and The Column Churches." Cahiers Archéologiques 24 (1975): 115-135.

Firatl1, Nezih. La Sculpture Figurée an Musée Archéologique d'Istanbul. Ed. Catherine Metzger vd., Paris: Jean Maisonneuve Éditeur, 1990.

Frantz, M. Alison. "Byzantine Illuminated Ornament: A Study in Chronology." Art Bulletin 16/1 (1934): 43-76.

Gavrilović, Anđela Đ. "The Representation Of Constantinople On The Folio 145r/b Of The Manuscript Of Madrid Skylitzes Synopsis Of Histories." International Symposium of Byzantologists Nis and Byzantium IV, Ed. Miša Rakocija (Nis: Cultural Center of Nis, 2016): 373-382.

Igorevna, Leshcheva Yana. "Whirling Disc" in the Byzantine Iconography. Search for Meaning." Science Journal of Volgograd State University. History. Area Studies. International Relations 19/ 3 (2014): 35-44.

Jerphanion, Guillaume De. Une Nouvelle Province de l'art Byzantin: Les Eglises Rupestres de Cappadocia 1.2. Paris: Librairie Orientaliste Paul Geuthner, 1932.

Karahan, Anne. "Beauty in the Eyes of God. Byzantine Aesthetics and Basil of Caesarea." Byzantion 82 (2012): 165-212.

Karahan, Anne. "The Image of God in Byzantine Cappadocia and the Issue of Supreme Transcendence.” Studia Patristica 7 (Leuven-Paris-Walpole: Peeters Publishers, 2013), 97-111. 
Katsafodos, St. Panayonis. "New Epigraphic Evidence From Mani The Kaphiona Epigrams." Deltion tes Christianikes Archaiologikes Hetaireias 38 (2017): 1-43.

Kaya, Metin. "Reflection of The Islamic and Sassanid Art on the Aniconic Decoration of Byzantine Wall Paintings in Cappadocia." International Symposium of Byzantologists Nis and Byzantium XVIII, Ed. Miša Rakocija (Nis: Cultural Center of Nis, 2020): 339-346.

Levy, Catherine Jolivet. "Bezirana Kilisesi (Cappadoce). Un Exceptionnel Decor Paleologue en teres de Rum. Nouveau temoigage sur les relations entre Byzance et Le Sultanat." Zograf 41 (2017): 107-141.

Maurice, Didron. The History of Christian Art in The Middle Ages I. Çev. E. J. Millington. London: Henry G. Bohn, York Street, Covent Garden, 1851.

Milovanovic, Bebina ve Jelena Anđelković Grašar. "Female Power That Protects: Examples of The Apotropaic and Decorative Functions of The Medusa in Roman Visual Culture From The Territory of The Central Balkans.” Starinar 67 (2017): 167-182.

Mouriki, Doula. "The Mask Motif in the Wall Paintings of Mistra. Cultural Implications of a Classical Feature in Late Byzantine Painting." Deltion tes Christianikes Archaiologikes Hetaireias 10 (1980-1981): 307-338.

Nersessian, Sirarpie Der. Miniature Painting in the Armenian Kingdom of Clicia from the Twelfth to the Fourteenth Century Vol. II. Washington D.C.: Dumbarton Oaks Research Library and Collection, 1993.

Ousterhout, Robert. Visualizing Community, Material Culture And Settlement in Byzantine Cappadocia. Washington: Dumbarton Oaks Research Library And Collection, 2017.

Öney, Gönül. "Sun and Moon Rosettes in The Shape of Human Heads in Anatolian Seljuk Architecture." Anatolica III, (1969-1970): 195-203.

Podskalsky, Gerhard. "Eschatology." Oxford Dictionary of Byzantium, Vol. I. Ed. Alexander Khazdan. New York: Oxford Press, 1991, 728.

Quinones, Ana Maria. Symboles Végétaux: La Flore Sculptée Dans L'art Médiéval. Paris: Desclée de Brouwer, 1995.

Ratseva, Avetozara, Velike Tarnovo. "The Mural Spinning Discs an Indication for Spiritual Connections and Artistic Influences.” Series Byzantina XI (2013): 25-40.

Restle, Marcell. Byzantine Wall Painting n Asia Minor 1. Shannon: Irish University Press, 1967.

Schwartz, C. Ellen. "The Whirling Disc: A Possible Connection between Medieval Balkan Frescoes and Byzantine Icon.” Zograf 8 (1977): 24-29.

Svetozar, Radojčić. Mileševa, Beograd: Srpska književna zadruga, 1963.

Tanman, Mehmet Baha. "Beylikler Dönemi Anadolu Türk Mimarlığının İncelenmemiş Bir Ürünü: Korkuteli Alaeddin Camii.” Beylikler Dönemi Kültür ve Sanatı Sempozyum Bildiri Kitabı. İstanbul: Sanat Tarihi Derneği Yayınları, 2014, 163-183.

Trilling, James. The Language of Ornament. New York: Thames \& Hudson Ltd, 2001.

Uyar, B. Tolga. "Carving, Painting, and Inscribing Sacred Space in Late Byzantium Bezirana Kilisesi Rediscovered (Peristrema-Cappadocia)," Architecture and Visual Culture in the Late Antique and Medieval Mediterranean. Ed. Vasileios Marinis, Amy Papalexandrou ve Jordan Pickett. Turnhout: Brepols Publishers, 2021, 207-222.

Warland, Rainer. Byzantinisches Kappadokien. Darmstadt / Mainz: Verlag Philipp von Zabern, 2013. 
Yalçın, Asnu Bilban. "Materiali di eta Paleologa nel Museo Archeologico di Istanbul," L'arte di Bisanzio e l'Italia al tempo dei Paleologi, Milion Studi e Ricerche di Arte Bizantina 5. Roma: Argos, 1999, 359-382.

Yalçın, Asnu Bilban. "Bizans Estetiğine Giriş.” Değişen Tarihsel Süreçler Değgişen Kavramlar. Ed. Kiymet Giray. Ankara: Ankara Üniversitesi Basımevi, 2008, 47-61.

Apotropaico. "Treccani.” Erişim 11 Haziran 2021.

https://www.treccani.it/enciclopedia/apotropaico

Zodiac painting on caldarium dome. "Molon." Erişim 14 Ocak 2021.

https:/www.molon.de/galleries/Jordan/Castles/Amra/img.php?pic=7 
